\title{
ROLE OF HEADQUARTER ATTENTION DISPARITY ON EXPATRIATE KNOWLEDGE SHARING BETWEEN ASSIGNMENTS
}

\begin{abstract}
A thesis submitted in fulfillment of the requirements for the degree of
\end{abstract}
Master of Commerce in International Business (IBUS592)

by

SACHINIE OSAKA WANASINGHE

300315815

Supervised by

DR YANG YU

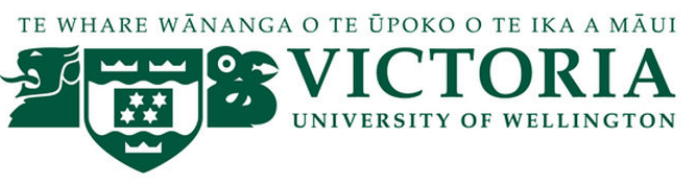

Victoria University of Wellington

2019 


\begin{abstract}
In acknowledgement of ongoing challenges in knowledge sharing, continuous research efforts are required to reflect the ever-changing landscape. Current research does not entirely encapsulate recent conceptualisations of multidirectional knowledge flows within the MNC, specifically from a lateral perspective. Accordingly, the role of expatriates reflect the importance of lateral knowledge sharing yet research has not holistically addressed the complex nature of exploiting such knowledge. Extensive examination of the HQ-expatriate relationship and repatriation process highlights the limited recognition for expatriates still within the expatriation cycle (i.e. moving from subsidiary to subsidiary).
\end{abstract}

This thesis seeks to add to the existing literature by exploring a potential new antecedent, headquarter attention disparity. The attention-based view of the firm reflects subsidiary level outcomes of unequal distribution of HQ attention. Extending this to explore the role on expatriate knowledge sharing is novel. The research implements a hermeneutical research design using semi-structured interviews. These sought to discover expatriate conceptualisations of lateral knowledge sharing and the related perceptions of HQ attention disparities between subsidiaries. The study draws on the ability-motivation-opportunity framework within a knowledge sender-receiver context. Expatriates coming from high-HQ attention subsidiaries demonstrate their own understanding of the acquired knowledge, influenced by individual context. These same interpretations guide subsidiary willingness to learn and the nature of knowledge sharing interactions. The results illustrate these opinions of perceived benefits to impact the inclination for knowledge sharing. Where perceptions align, there is reduced uncertainty in the expatriate-subsidiary colleague relationship whereas diverging perceptions weaken the propensity to learn and expatriates' knowledge sharing risks deterioration. These outcomes are further susceptible to external effects. The first being perceived competence-trust in shared functional identity, the second through affect-trust within subsidiary socialisation efforts. 


\section{ACKNOWLEDGEMENTS}

Thank you to the School of Marketing and International Business who provided compassion, support and most importantly, free coffee throughout my postgraduate journey.

Thank you to my supervisor, Dr Yang Yu whose knowledge and guidance I could not have completed this thesis without.

A final thank you to my family and friends. Thank you to my parents for pushing me to reach my potential, especially my Ammi for all that she does; and Jake, for remaining positive when I could not.

To my dear friend, Jamie, our caffeine induced, meme referencing, and dare-fuelled sessions saw us through to the light at the end of the tunnel. I will forever be grateful of our friendship over the last year. 


\section{CONTENTS}

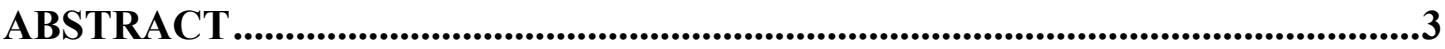

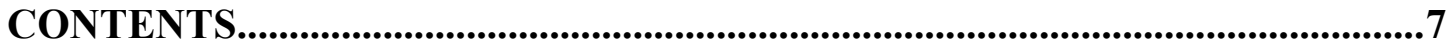

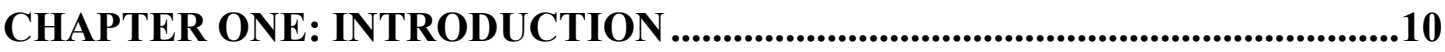

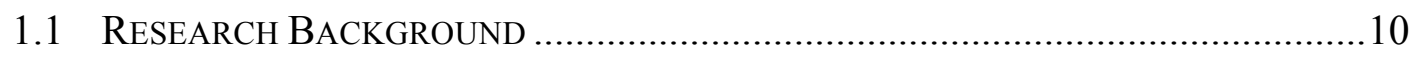

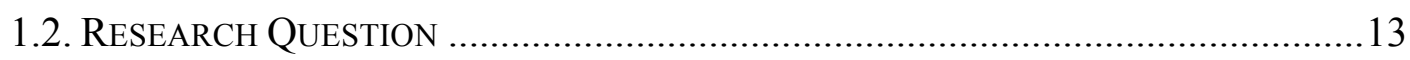

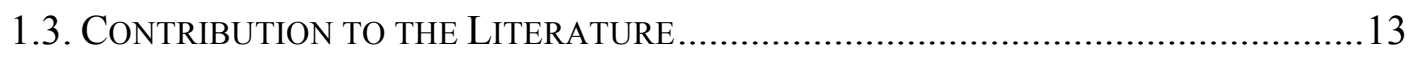

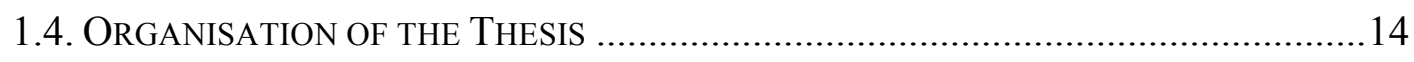

CHAPTER TWO: LITERATURE REVIEW ................................................15

2.1. ORGANISATIONAL LEARNING IN MNCS .........................................................15

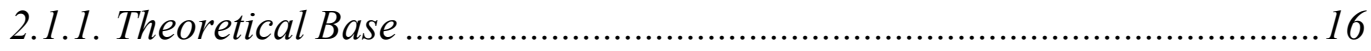

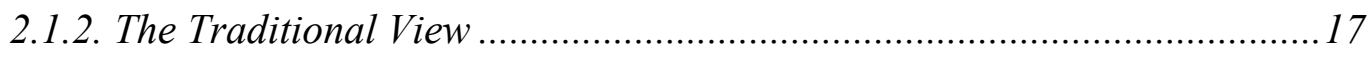

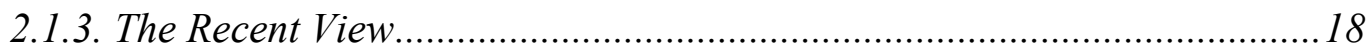

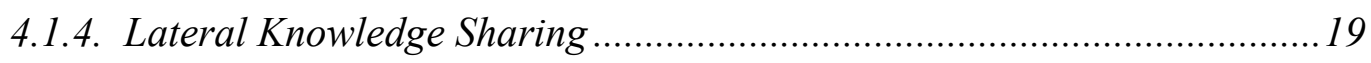

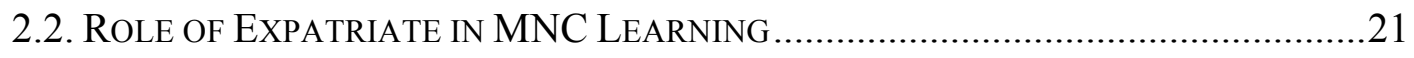

2.2.2. Role of Expatriate in Knowledge Sharing ................................................22

2.3. ANTECEDENTS OF EXPATRIATE KNOWLEdGE SHARING ...................................23

2.3.1. Sender and Receiver Characteristics....................................................23

2.3.2. Organisational Culture and Climate ...................................................25

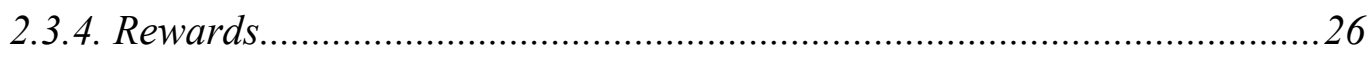

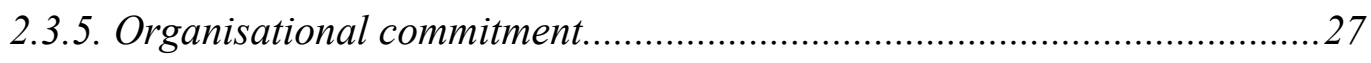

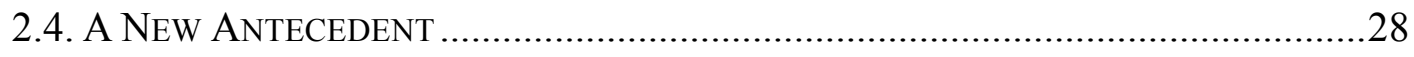

2.5. Role Of HeAdQuarter AtTEnTION IN MNC LEARNING ...............................28

2.5.1. The Attention Based View of the Firm ...................................................29

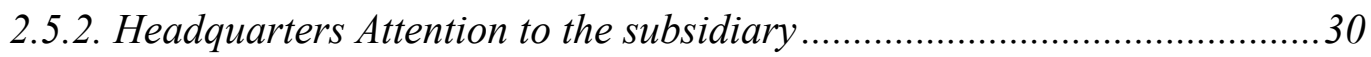

2.5.3. Perception of Attention Selection........................................................... 32

2.5.4. Perception of Attention Perspective.......................................................... 33

2.5.5. Perception of Attention Engagement ..................................................... 34

2.5.6. Effect of HQ Attention on Knowledge Sharing ........................................ 35

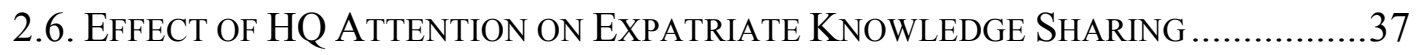


CHAPTER THREE: METHODOLOGY .............................................................39

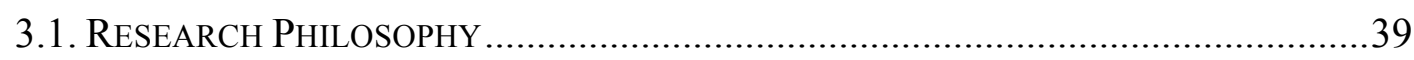

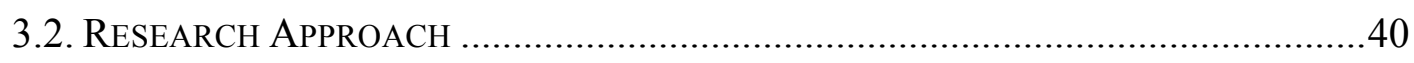

3.2.1. Use of In-Depth Semi-Structured Interviews .........................................41

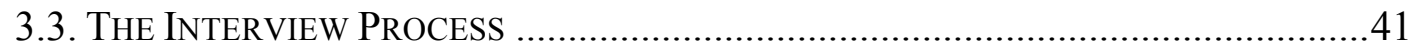

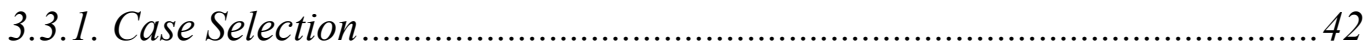

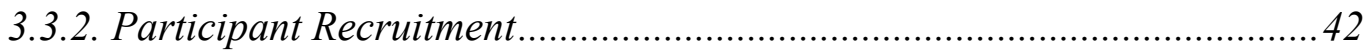

3.3.3. Participant Characteristics................................................................ 43

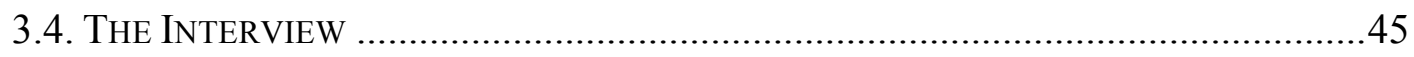

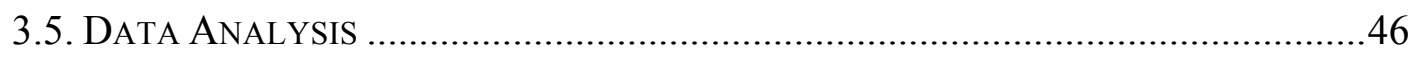

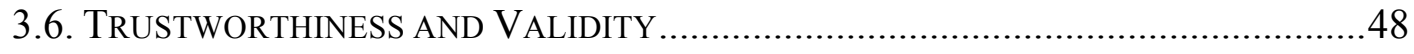

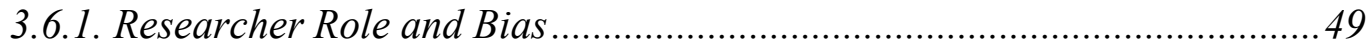

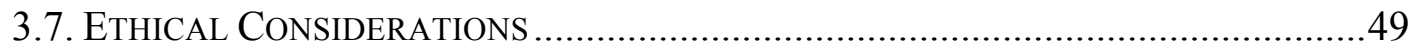

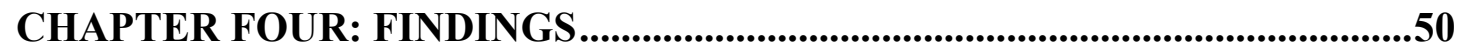

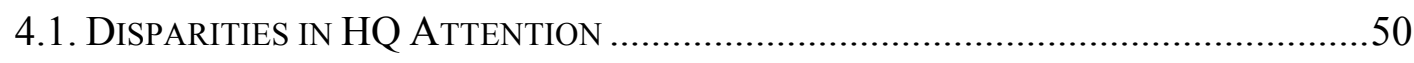

4.2. HQ ATtEnTION DisParity AND EXPATRIATE KNOWLEDGE SHARING ..............52

4.3. EXPATRIATE Perception of KNOWLEDGE ACQUiRED From PreVious

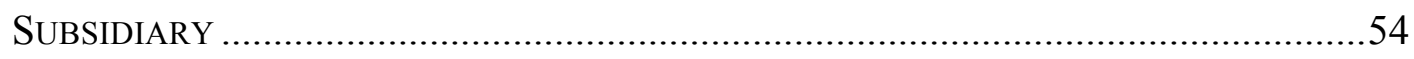

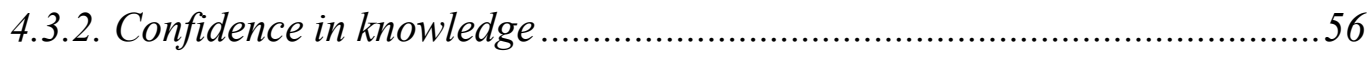

4.4. SUBSEQUENT SUBSIDIARY PERCEIVED VALUE OF KNOWLEDGE FROM PREVIOUS

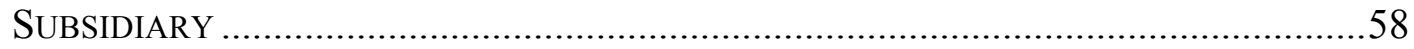

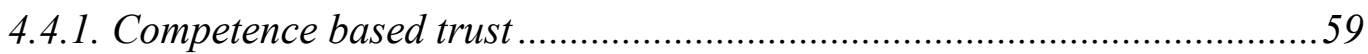

4.4.2. Expatriate perception of current subsidiary receptivity ...........................61

4.5. CONTINGENCY OF THE RELATIONSHIP BETWEEN HQ ATTENTION AND

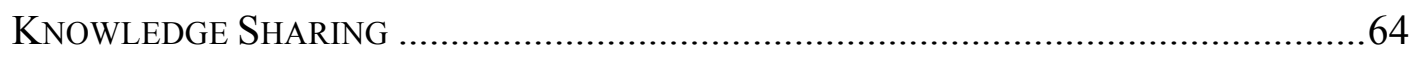

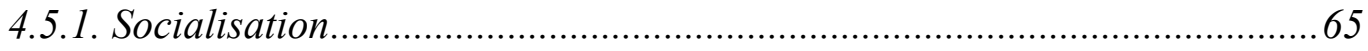

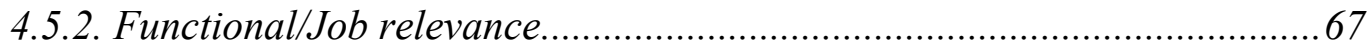

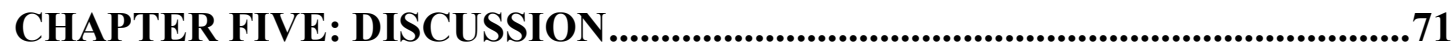

5.1 EFFECT OF HQ AtTENTION ON ExPATRIATE KNOWLEDGE ................................72

5.2 Effect of Expatriate Perceived Value of Knowledge on KS..................73

5.3 SubSequent Subsidiary’s Perceived Value of KnOwledge .......................74

5.4. EFFECT OF S2 PERCEIVED VALUE OF KNOWLEDGE ON KS ................................76 
5.5. CONTINGENCY OF THE RELATIONSHIP BETWEEN HQAD AND KNOWLEDGE

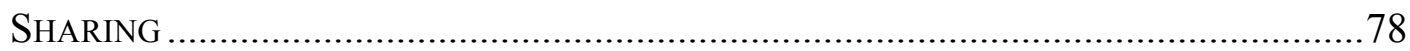

5.5.1. Effect of Socialisation on Motivation to Share Knowledge .......................78

5.5.2. Effect of socialisation on subsidiary receptivity ........................................ 79

5.5.3. Effect of Job/ functional relevance …….................................................8 80

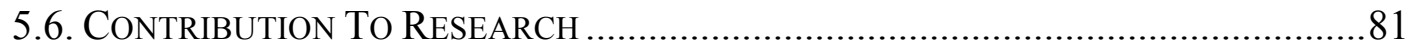

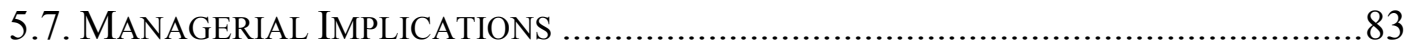

5.8. LIMITATIONS AND FUTURE DIRECTIONS FOR RESEARCH ...................................83

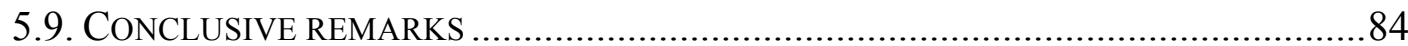

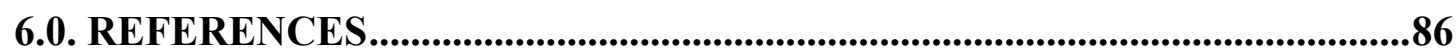

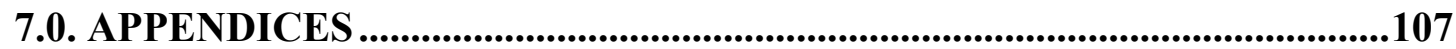

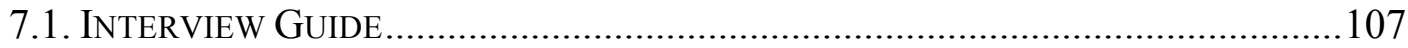

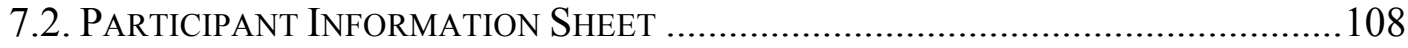




\section{CHAPTER ONE: INTRODUCTION}

In this chapter the research background will be presented in order to provide readers with a contextual background of the focal topic. This is followed by a discussion around the research problem and thus leading to the derived research question the thesis seeks to address. Key contributions of the study will then be summarised as conclusive remarks.

\subsection{Research Background}

Knowledge is a priceless asset of the multinational corporation (MNC) (Gao and Riley). In today's expanding competitive economy, knowledge management functions are considered the cornerstone in exploiting and sharing knowledge more effectively than competitors (Porter, 1990; Wang et al., 2006). Modern scholars characterise MNC success as being attributed to the sharing and utilisation of knowledge (Nonaka and Takeuchi, 1995, 2011; Tsai, 2001), the fundamental principle of which is to move knowledge from one party to another (Easterby-Smith et al., 2008).

Theoretically, the MNC is conceptualised as a relationship network of subsidiaries. Successful knowledge sharing (KS) is contingent on the MNC's ability to utilise knowledge repositories and share knowledge from one department to another. Research has since explored the dyadic knowledge flow from a multinational's HQ to subsidiaries and vice versa. Outside this vertical context, $\mathrm{KS}$ is known to occur in a multidirectional fashion, including lateral movements i.e. subsidiary to subsidiary. Some studies have referred to the knowledge sharing behaviour of the entire subsidiary whilst others have specifically referred to the individual knowledge transporters.

Accordingly, International Business literature recognise the significance of diffusing knowledge by arguing it to be the key purpose of international assignments. This emphasises the value of expatriates who are considered individual knowledge repositories in the context of international assignments. While extant research has focused on the passing of knowledge from HQ to subsidiaries or sharing business opportunities from subsidiary to $\mathrm{HQ}$, our study merges with the more recent research characterising the subsidiary as an important knowledge stock. Under the assumption 
of firm internationalisation, subsidiary locations somewhat implies the potential to generate desirable information that are perceived as advantageous for other subsidiaries to learn from. Hence, for a subsidiary to further strengthen their own knowledge base, it is necessary for employees within to learn from acquired experiences of other colleagues in and between the various parts of the organisation. As such, the research is salient in highlighting the important role of expatriates as knowledge transporters between. Research has subsequently examined the various contextual determinants required in order to exploit expatriate knowledge in the HQexpatriate, or expatriate-home unit (repatriation) relationship. Reflective of the call for more research to explore lateral knowledge sharing outcomes, it is also interesting that little is acknowledged regarding the individuals still moving within the expatriation cycle (i.e. across subsidiary assignments). As such, antecedents to knowledge sharing have accumulated significant scholarly interest, exploring the fundamental questions of what facilitates and inhibits the sharing of knowledge (van Wijk, Jansen and Lyles, 2008). At the firm level, several influential factors have since been discovered such as knowledge characteristics, sender and receiver characteristics (Bartlett and Ghoshal, 1990; Gupta and Govinjaran, 2000; Argote et al., 2000), managerial action properties (Cabrera, Collins, and Salgado, 2006), corporate culture (Ipe, 2003). Aligned with sender/receiver characteristics, the known individual level antecedents include sender and receiver absorptive capacity (Minbaeva et al., 2004) personality traits (Cabrera et al., 2006; Mooradian et al., 2006; Wang and Yang, 2007) and goal orientations (van Wijk al., 2008; Swift et al., 2010).

Across the current knowledge, it is widely accepted that the level of social capital within relationships often reflects the success of inter-MNC knowledge sharing. Evidently, this implies some HQ-subsidiary relationships generate more synergisties than others, which may have the potential to influence the outcomes of knowledge sharing at both the firm and individual level. Therefore this thesis addresses the call for further research to be done to reduce the lateral knowledge sharing literature gap whilst adding to what is known of determinants of knowledge sharing at the individual knowledge.

Scholars remain aware of the relative benefits subsidiaries accumulate through prolonged exposure to headquarters; including resources, investment, network 
connections and feedback. However there is a lack of support directly linking subsidiary performance to $\mathrm{HQ}$ attention. Nonetheless, The ABV of the firm emphasises the unequal distribution of headquarters attention as a by-product of subsidiary weight and voice (Bouquet and Birkinshaw, 2008). This implies the level of headquarters' attention as contingent on strategic configuration of the subsidiary and market location. In the context of this thesis, the disparity of HQ attention inherently supports the argument for the existence of highly synergistic HQsubsidiary relationships relative to others within the same multinational. It is largely understood these unique advantages are beneficial to share to other units of the MNC thus compelling the need to utilise lateral knowledge flows.

On the other hand, literature has lightly touched on the impacting role of headquarter involvement in improving subsidiary reverse knowledge sharing, using expatriates. Some research recalls the efforts expatriates make to "sell" the subsidiary in order to attract headquarters' attention toward opportunities and engage (Plourde et al., 2014; Ocasio, 2011; Monteiro, 2015). This stream of research recognises the severe restrictions subsidiaries face in their ability to engage in KS without the cooperation of headquarters (Holm, Pedersen and Björkman, 2000; Ciabuschi et al., 2011; Dellestrand, 2011). Conversely, very little is known about the inverse i.e. the effect headquarter attention a subsidiary receives has on expatriate knowledge sharing outcomes. Once again, the known linkages between HQ attention and knowledge sharing are largely examined in a vertical context at firm level despite recognition that the actual knowledge sharing process requires the engagement of individuals which are subject to factors that influence the individual psyche (Argote and Ingram, 2000; Cabrera et al., 2006).

Amalgamating the key gaps found; the current research spans across different disciplinary fields primarily the knowledge sharing and the attention-based view. A novel integration of these two profound streams of literature leads the thesis to explore the role of observed HQ attention disparity between subsidiaries on expatriate lateral knowledge sharing behaviour using case studies. The expected contributions of this paper are to create an increased awareness of the neglected lateral knowledge sharing process and to broaden the current research on antecedents of knowledge sharing. 


\subsection{Research Question}

While the world continues to experience surges in mobility and individual expertise, the expectation for research to address the full nature of the KS process is unrealistic. However, it has sparked research toward understanding enabling and inhibiting factors. The rationale for this research is to investigate a new possible antecedent of expatriate knowledge sharing that has arguably yet to be linked. In light of the literature on MNC knowledge flows, it struck the researcher that expatriates who relocate to another subsidiary before completing the expatriation cycle have been overlooked. The inherent assumption of knowledge flows remains that to increase the current knowledge base of a subsidiary; it is necessary for employees within to learn from acquired experiences of other colleagues in and between the various parts of the organisation (Toh \& DeNisi, 2005). This is a further reflection of the lack of literature on lateral knowledge sharing. Consequently, the research overlooks knowledge sharing under these unique circumstances. This thesis extends the current research on both knowledge sharing and the ABV by integrating the effect of HQ attention at firm level to aspects associated with knowledge sharing at the expatriate level, between assignments. The purpose of the study is therefore addressing the following exploratory research question:

What is the role of headquarter attention disparity on expatriate knowledge sharing behaviour between subsidiaries?

Recruiting multiple case studies using personal networking and online advertising, the researcher conducted 18 semi-structured interviews using a hermeneutical approach. This entices in-depth descriptions of expatriate knowledge sharing, and their observations of headquarter attention disparities. Thus gaining further insight into determinants of expatriate knowledge sharing from the angle of the key actor in the process.

\subsection{Contribution to the Literature}

The key contributions of the thesis are as follows. Firstly, the study further extends research on the role of expatriates as transporters of knowledge across MNC units, specifically those still within the expatriation cycle, moving between subsidiaries. In 
doing so, the thesis explores lateral knowledge sharing of the expatriate as a reflection of the dearth of literature surrounding firm level lateral MNC knowledge flows. Secondly, the thesis extends the attention-based view as a determinant of subsidiary actions to a new domain within the knowledge-sharing context. More specifically, exploring the effect firm level outcomes such as HQ attention disparity within the context of individual knowledge sharing outcomes. Taking into account the current antecedents of expatriate knowledge transfer to date (Oddou et al., 2009), the proposed research seeks to explore the role of HQ attention disparity as a new possible antecedent of expatriate knowledge sharing. Arguably, this is the most novel contribution as the two streams of literature are yet to be adequately researched in conjunction to one another.

\subsection{Organisation of the Thesis}

This thesis is organised into five chapters, inclusive of the current chapter Introduction. Chapter Two presents an in-depth review of the current literature across key variables. Firstly, it reviews the literature on MNC knowledge flows as an

organisational process before addressing the role of expatriates. The streams of research related to the attention-based view (ABV) are discussed before subsequently linking to knowledge sharing. In summary of the review, this chapter will highlight the presenting theoretical gaps this thesis seeks to address. Chapter Three sheds light on the qualitative research design. The purpose of the research is stated in relation to the data collection process and sampling methods. Thereafter, Chapter Four analyses the data extracted from the qualitative sample and findings of key themes are highlighted. Chapter Five begins with presentation of the derived framework and further discusses the key findings. The contributions of the study are then stated in conjunction with managerial implications. The chapter concludes the thesis with final remarks and acknowledges limitations as well as presenting recommendations for future research. 


\section{CHAPTER TWO: LITERATURE REVIEW}

The following chapter sets the context across all key variables beginning with MNC knowledge flows. We introduce the traditionalist perspective whereby knowledge sharing was largely attributed to HQ control. Subsequently, we review the recent shift toward current views of knowledge sharing, accentuating the realised multidirectional nature of MNC knowledge flows and utilisation of expatriates. The chapter concludes with a review on known antecedents of knowledge sharing and introduces a novel linkage to the ABV.

\subsection{Organisational Learning in MNCs}

Knowledge has become a vital concern for the MNC, as the ability to share knowledge is one of the fundamental sources of competitive advantage (Doz, Santos and Williamson 2001). Organisational learning is defined as a combination of improving actions and acquiring new knowledge that are of strategic importance (Saka-Helmhout, 2007). In the international context, a major advantage of organisational learning is the created synergies developed from cross-border creation, and sharing of knowledge (Bartlett and Ghoshal, 1989; Gupta and Govindarajan, 2000; Saka-Helmhout, 2007). Three inter-related features of multinational organisational learning exist. Firstly, the MNC possess potential to create-firm specific advantages resulting from its network of operations across different countries. This incorporates the ability to exploit joint production economies (Kogut and Kulatilaka, 1994) and higher bargaining power with key stakeholders. Secondly, more so than indigenous firms, MNCs are faced with a higher level of operational complexity that makes it more challenging to exploit knowledge globally. The final feature is the capacity to knowledge generate. The MNC may uncover better techniques when conducting business internationally (Van Maanen and Laurent, 1993). Suggestively, these firm-specific assets are linked to a degree of knowledge. The critical question is how to exploit such knowledge across MNC operations.

Accordingly, among the many benefits of internationalisation, the importance of knowledge sharing has been frequently addressed in scholarly theories, paradigms and 
models (Dunning, 2001; Rugman, 2006; Vahlne and Johanson, 2014). The concept of knowledge sharing is therefore important enough to garner attention, thus demonstrating the need for a better understanding of its flows in the context of the MNC. Literature asserts there are numerous means organisational learning can occur. More known, is the relationship and learning between parent and subsidiary networks, which can be used to acquire and transfer knowledge by exploiting expertise within the MNC. Inkpen (1998) argues the importance of intra-MNC networks as they enhance the likelihood of knowledge possessed by individuals being shared across the MNC. As an example being, internal knowledge transfer between subsidiaries showing positive influence on innovation (Hansen et al., 1999; Tsai 2001), coordination of global operations and strategy, better processes and organisational best practices (Kostova and Roth 2002; Szulanski 1996).

\subsubsection{Theoretical Base}

Scholars advocate the importance of using sophisticated knowledge management systems in conjunction with informal networks between MNCs' units, as a key in turning potential advantage to a realised one (Ensign, 1999). Knowledge is described as being "broader, deeper and richer" than mere information, occurring through actions (Tsoukas and Mylonopoulos, 2004). It is realised when used as a medium, encompassing situation specific factors, values, experiences and most importantly facts that create a framework to adopt new information. A person with expertise in a certain field is able to create new knowledge and solutions (Bender and Fish, 2000). Therefore it is understandable, that these different forms of knowledge are managed different within the MNC.

Accordingly, knowledge is considered dyadic in nature, having both explicit and tacit distinctions (Osterloh and Frey 2000). A necessary combination of formal and informal networks is widely acknowledged to facilitate the diffusion of both forms (Gupta and Govindarajan, 2000). Explicit knowledge is easily retrieved and communicated (Hau et al. 2013). Conversely, tacit knowledge is seen as more intuitive and is part of an individual's cognitive thought and perceptions (Suppiah and Sandhu 2011), shared through close proximity relationships, which extend over a period of time. Thus, it is harder to formalise and express to others (Nooshinfard and 
Nemati-Anaraki 2014; Riusala and Suutari, 2004) as it is linked to abilities and action that are acquired through practical experience (Foos et al., 2006).

Tacit path-dependent knowledge in particular is difficult to adopt by competitors therefore a strategically significant resource for the MNC (Argote and Ingham, 2000). Explicit knowledge provides the building blocks, while tacit knowledge provides the glue (Dhanaraj et al. 2004). Therefore, rather than scrutinising separately as polar characterisations, the thesis addresses explicit and tacit characteristics of knowledge as simultaneously occurring dimensions. Virta (2011) asserts that these dimensions are unified in the social practices of an MNC as both are intertwined in achieving organisational objectives (Crowne, 2009). The benefit of informality is that it allows for technical knowledge and remedies to be widely shared throughout the organisation (Brown and Duguid, 2001), as well as playing a significant role in the diffusion of tacit knowledge.

\subsubsection{The Traditional View}

Intra-organisational learning networks can span business units and may be constituted on an informal basis (Tregaskis, 2003). The strategic imperative of the MNC according to Kogut and Zander (1992) is often characterised by leveraging dispersed knowledge-based assets (Doz et al., 2001). Headquarters have traditionally been the distinguishing feature of the MNC. Its role was to "coordinate, appraise and plan goals and policies", on the one hand, and to "allocate resources" on the other. This distinction was expressed further by referring to the "entrepreneurial function" and the "administrative function" of HQ (Chandler, 1991) based on goals aimed at achieving specific organisational objectives (Tsoukas and Vladimirou 2001).

The value creating function goes hand in hand with the concept of parenting advantage (Nell and Ambos, 2013). This highlights the potential relevance of HQ to subsidiaries and to the MNC as a whole when achieving superior performance. The parenting advantage henceforth relating to knowledge sharing activities as it states what can be achieved by bringing subsidiary activities under the direct control of HQ rather than letting them operate autonomously. As such, a substantially developed research repository focuses on the headquarter-subsidiary relationship. Subsidiary 
role perspective (Birkinshaw, 1997) also utilised the parent perspective. Accordingly, this perspective regarded the nature of the headquarters-subsidiaries relationship as dictated by headquarters and the roles of subsidiaries are determined by the parent company (Bartlett and Ghoshal, 1986; Jarillo and Martinez, 1990). The traditional perspective in a sense builds on the notion that headquarters role facilitates the sharing of competence across units in a forwards direction (Collis and Montgomery, 1998). The perspective encompasses three main mechanisms, the first two being distribution of decision-making rights and resource allocation (Ghoshal and Barlett, 1990). This is concomitant with a perspective that the HQ role is to plan and design overall knowledge related activities rather than having a direct involvement in the activities. Accordingly, the third mechanism is related to the active intervention of HQ in the knowledge sharing process. This is in line with the traditional research arguing that the "direct" and forward involvement by corporate HQ is considered to be value creating (Chandler, 1991; Nell and Ambos, 2013).

Similarly, Dunning (1998) traditionally theorised that multinational knowledge sharing activities were centralised. MNCs generated knowledge for innovative activities through home base R\&D by the parent company or headquarters. Extending from the home market, HQ would set up subsidiaries (often Greenfields or acquired host country subsidiaries) in order benefit from this knowledge. Hence MNC knowledge flows was a one-way internal transfer of knowledge. This concept was known as the "centre-for-global" innovation strategy (Ghoshal and Bartlett, 1997) as knowledge centrally located in the headquarters of MNCs is transferred to foreign subsidiaries.

\subsubsection{The Recent View}

Headquarters has been theorised as responsible for the bulk of the MNCs value creation and competitive advantages (Chandler, 1991; Ciabuschi, Dellestrand, and Nilsson, 2015). Subsidiaries were accordingly perceived as knowledge receivers and inferior to HQ on several dimensions, including value of possessed knowledge (Michailova and Mustaffa, 2012). However, subsidiaries have been increasingly contributing to the company's value creation (Chung, 2014; Ciabuschi et al., 2015; Frost and Zhou, 2005). Cuervo-Cazurra and Un (2004), state strategic international 
resources that are firm specific can derive not only from a parent company advantage but also from a subsidiary advantage. Recent research has since recognized the critical importance of strategically locating and leveraging knowledge resources from subsidiaries in a reverse flow of knowledge (Bartlett and Ghoshal, 1989; Criscuolo and Narula, 2007; Frost and Zhou, 2005). Accumulated knowledge from on-going interactions can be used to develop the subsidiary's knowledge base further. Accordingly, each individual subsidiary is embedded into a unique local network therefore exposed to new ideas and opportunities (Andersson et al., 2002).

A growing body of research now exists having investigated the relationship between HQ-subsidiary and reverse knowledge transfers (e.g., Ambos et al., 2006; Gupta and Govindarajan, 2000; Håkanson and Nobel, 2000; Yang et al., 2008). These new knowledge flows have since been linked to various theories such as those proposed by (Szulanski, 1996) and (Kostova, 1999) to examine the factors that influence the access to and transfer of subsidiary knowledge (Reiche , Harzing , and Kraimer , 2009; Yang et al., 2008). Different subsidiary entry modes are also considered pretransfer factors influencing the reverse knowledge transfer. Greenfield entry for example implies greater dependency on parent company knowledge thus lowering the potential for reverse knowledge transfer (Najafi-Tavani et al., 2012), whereas an acquisition may imply new stocks of knowledge to be transferred to headquarters (Gupta and Govindarajan, 2000; Najafi-Tavani, Axèle, and Sinkovics, 2012). Nonetheless, complexities may arise as acquisitions and also alliances often encounter different culture and routines which can make reverse knowledge sharing challenging (Öberg, 2013).

\subsubsection{Lateral Knowledge Sharing}

The literature presents an abundance of research acknowledging forwards and reverse knowledge sharing flows. As the current business climate calls for MNC's to differentiate their services, this study bounds its focus on lateral knowledge sharing (subsidiary-subsidiary). This process has become increasingly important as HQ dedicate more resources to subsidiary managers in response to escalated competition (Luo and Zhao, 2005;Wang and Noe, 2010). In order to utilise synergistic behaviours, firms engage in cross-unit sharing of knowledge to reflect their distinctive 
competencies. However, lateral knowledge sharing research remains underexplored in spite of its growing importance to the knowledge generation and competitiveness of the MNC (Gupta and Govindarajan, 2000; Frost and Zhou, 2005; Chung, 2014). Luo and Zhao (2005) in their research on inter-unit knowledge sharing explored subsidiary knowledge sharing behaviour with other subsidiaries under different circumstances. They found that knowledge sharing between subsidiaries is largely contingent on the subsidiary's strategic interdependence and linkages with the parent firm and peer members. Meanwhile, other studies addressed how subsidiary knowledge sharing is shaped by external conditions such as institutional deterrence, regulatory interference, environmental hostility, liability of foreignness, and intellectual property rights protection (Kostova 1999).

Moreover HQ as the only valuable source of information, internal MNC knowledge is a valuable way to get input into the development of the subsidiaries own knowledge base. This aligns with concepts of the geocentric firm (Perlmutter, 2017), and the transnational corporation (Bartlett and Ghoshal, 1989), who posit that knowledge is generated in all parts of the $\mathrm{MNC}$, shared across the entire corporation, including headquarters and its other foreign subsidiaries. It is theorised that knowledge sharing from other parts of the MNC has the potential to contribute to the absorptive capacity of the subsidiary i.e. the willingness to learn and utilise new information. The subsidiary is characterised by various sources of intellectual capital and knowledge repositories (Wright, Dunford, and Snell, 2001). Few studies have categorised these other sources into human capital and social capital. The former refers to the combined skills and expertise held by employees as a type of knowledge stock, which can be leveraged under certain circumstances (Hatch and Dyer, 2004). Whereas social capital refers to the multi-faceted sum of potential knowledge resources derived from the network of relationships possessed by an individual or unit. Nahapiet and Ghoshal (1998) identified three dimensions: (1) the structural dimension represents the pattern of relationships between parties; (2) the relational dimension represents the development of relationships other over time (e.g. such as respect, friendship, trust, and norms) and (3) the cognitive dimension, which signifies shared interpretations.

These lateral directional flows of knowledge transfer encompass the abilitymotivation-opportunity framework which lies very similar to conceptual theories 
proposed by Szulanski (1996) and Kostova (1999). Szulanski (2003) later identified three barriers: (1) the difficulty of the relationship between the sender and the recipient, (2) the recipient's lack of absorptive capacity or the ability to adopt and apply the given knowledge, and (3) causal ambiguity or the recipient's lack of understanding the importance of the knowledge to carry out his/her duties and responsibilities. This accentuates the importance of recipient's ability and willingness to comprehend knowledge, before it can be considered transferred (Kang and Hau, 2014). Similar streams of research such as Kogut and Zander, (1996) also focused on reasons of knowledge transfer stickiness as did Riusala and Smale (2007) who found that stickiness may be caused by (1) the host unit's weak absorptive capacity, (2) the teaching of the knowledge, or (3) the complexity. Overall the research has been a useful lens to start examining the factors that influence the access to and transfer of host-unit knowledge (Reiche et al., 2009; Yang et al., 2008).

Taken outside of this context however, reverse and lateral knowledge transfer although is often looked at from the subsidiary level and perspective, it paves way for research focused toward the transporters of knowledge in such circumstances (Ambos, Ambos, and Schlegelmilch, 2006; Nery-Kjerfve and McLean , 2012; Yang et al., 2008). Although knowledge can be expressed through processes, the literature strongly acknowledges knowledge is created and shared within an individual context (Tsoukas and Mylonopoulos, 2004). As the review notes the multifaceted nature of the knowledge, it provides an understanding as to why tacit knowledge is of extreme strategic importance (Bonache and Brewster, 2001; Fransson, Hakanson, and Liesch, 2011). Prized due to its value, rarity and inimitable characteristics this form of knowledge in turn characterises the value of the human transporters of knowledge (Leposky, Arslan and Kontkanen , 2016). From this we truly note the pivotal role of expatriates, and their role in the knowledge sharing process (Sanchez-Vidal, SanzValle and Barba-Aragon, 2016).

\subsection{Role of Expatriate in MNC Learning}

The business expatriate is defined as an employee of a multinational working in another country (Crowne, 2009). As the business environment becomes progressively internationalised, MNCs become compelled to frequently incorporate expatriate 
assignments as part of their human resource strategy to increase market knowledge and competitiveness (Crowne, 2009; Berthoin-Antal, 2000). Similarly, Oddou et al., (2009) consider expatriate assignments as opportunities to create economies of skills and develop knowledge from exposure to different environments, which can be used to benefit the rest of the MNC (Kamoche, 1997; Bonache and Brewster, 2001; Riusala and Suutari, 2004). Accordingly, expatriate assignments are considered expert work as it translates to self-controlled knowledge work, whereby education acts as a basis (Riusala and Suutari, 2004). It is considered more important to share situational and experiential tacit knowledge than explicit knowledge, which can be acquired by education (Virta, 2011). Hence, expatriates constantly develop skillsets beyond the mere acquisition of market facts and customers but to also include perspectives shifts, increased network knowledge, a more global mindset and improved personal competencies (Berthoin Antal, 2000; Bender and Fish, 2000; Minbaeva and Michailova, 2004; Oddou et al., 2013). Subsequently, the application of this knowledge enlarges subsidiary trajectory, thus contributing to the overall abundance of innovative resources available to the MNC (Hakanson and Nobel , 2001; Foss and Pederson , 2002; Mudambi , Piscitello , and Rabbiosi , 2014; Leposky et al., 2016; Nair, Demirbag, and Mellahi, 2016).

\subsubsection{Role of Expatriate in Knowledge Sharing}

Parallel to literature on MNC learning, the expatriate traditionally has acted as an agent of knowledge from headquarters to subsidiaries to coordinate control (Bonache and Brewster 2001). Reflecting similar shifts toward multidirectional MNC learning, the expatriate is now a vital transporter of tacit learning experiences and knowledge from also subsidiaries back to headquarters and/or other units (Harzing, 2001; Foss and Pederson, 2002). Henceforth the expatriate is justified as a critical element for the knowledge sharing process to occur (Harzing et al., 2016).

To understand how and why expatriates share their knowledge within the MNC, the knowledge sharing process must be examined. Studied within a behavioural approach framework of knowledge management $(\mathrm{KM})$, the KS process is not automatic, more rather highly contingent on human variables (Castañeda and Ignacio, 2015). KS behaviour of the individual has been committed to examining the role of people (i.e. 
the expatriate) on the creation, spreading and assimilation of knowledge. This involves extensive voluntary interactions sharing acquired raw knowledge with others. Specifically, sharing acquired competences, experiences, expertise, values, contextual information and insights, in order to create institutional frameworks for assessing and integrating new understandings and knowledge (Castañeda and Ignacio, 2015). Some studies summarise knowledge sharing as interaction in order to get tasks completed more effectively when conducted at the individual level whereas others reflect on sharing organisational competencies. The current study considers the two levels of knowledge sharing parallel to one another as the expatriate can make organisational experience based knowledge available to others through interpersonal interaction. However, integration of an expatriate's knowledge stock into the organisational context largely depends on the expatriate's knowledge sharing behaviour, which can be affected by a multitude of factors. The following section will address many of the current known antecedents of knowledge sharing as per the literature.

\subsection{Antecedents of Expatriate Knowledge Sharing}

The general dilemmas of expatriation and expatriates' difficulties in sharing and transferring knowledge during certain phases of international assignment have been under vast academic inspection (McEvoy and Buller, 2013). However, the literature has not fully accounted for the complexity of issues expatriates face when sharing knowledge. Therefore, the field seems to be scattered with results with limited research conducted to exhaustively create a complete view of expatriate antecedents of knowledge sharing. It is therefore needed to discuss what literature has uncovered as potential obstacles, which can hinder the knowledge or promote sharing within the MNC.

\subsubsection{Sender and Receiver Characteristics}

Knowledge sharing is manifested in the interpersonal socialisation therefore communicative skills with good abilities to cooperate in foreign environments are essential (Kaše et al., 2009; Reiche, 2012). On average, the expatriate processes vastly involve face-to-face interaction suggested to enable knowledge sharing (Oddou et al., 2009). Thus, literature suggests that individual characteristics explain why some 
engage in knowledge sharing whereas others do not. Fittingly, a consensus on knowledge sharing agrees the involvement of two parties, a knowledge sender or source, and one recipient (Kumar and Ganesh, 2009). The characteristics of the knowledge sender and the receiver are influential for effective knowledge sharing as both parties must be willing and capable to actually share and accept knowledge (Osterloh and Frey, 2000; Szulanski, 2000). Related to the cognitive aspects of social capital, shared identity can promote knowledge sharing behaviour as it strengthens the foundation needing to exist between sender and receiver in order for mutual understanding (Kane et al., 2005). Shared knowledge bases further enable KS due to commonalities, which make interpretation of information easier (Argote et al., 2003). A strong sense of group identity also influences individual knowledge sharing (Cabrera, 2003). Effective knowledge sharing demands collaborative efforts, implying that reliance is not only on the recipients' absorptive capacity (Zahra and George, 2002) but also very much on the knowledge sender's attitudes and behaviour.

Cabrera (2003) reviewed the main sociological and psychological theories to identify factors related to knowledge sharing behaviour at the individual level, specifically of knowledge senders (i.e. the expatriate). Nine factors were identified to have the potential to influence knowledge sharing behaviour. As the recent conceptualisation of the expatriate implies strong relationship qualities between knowledge sender and recipients, social capital comes to the forefront of how this can be achieved and has been articulated in much research (Kostova and Roth, 2002; Argote et al., 2003; Rhodes, Hung, Lok, Ya-Hui Lien, and Wu, 2008; Chang et al., 2012). Accordingly, trust is a strong predictor of knowledge sharing both within and between subsidiary units. Trust encourages risk taking and further facilitates successful cooperation and quality communication between source and receiver (Sankowska, 2013). Personality traits such as agreeableness, extroversion, conscientiousness, and openness, are all positively associated with the knowledge-sharing behaviour of individuals. However, norms are expected to have a direct influence of knowledge-sharing intentions whereas the personality factors are predicted to influence knowledge-sharing intentions indirectly through their impact on the individual's knowledge sharing attitudes (Caberera, 2003). Additionally, an individual will be motivated to share knowledge if they personally believe that the particular piece of knowledge is worth 
sharing or has potential benefit to the recipient (Cyr and Choo, 2010). Thus, beliefs regarding various individual competencies and skills are positively associated with the knowledge sharing behaviour of individuals (Cabrera, 2003).

\subsubsection{Organisational Culture and Climate}

Firm specific norms that encourage open exchanges among members lead to a greater degree of knowledge sharing. Openness to experience from the knowledge recipient is especially favourable (Cabrera et al., 2006; Mooradian et al., 2006; Wang and Yang, 2007). This facilitates obligation that an individual may feel toward KS and thus demonstrates a positive relationship to KS behaviour (Cabrera, 2003). With relation to the dyadic relationship, the type of interaction between knowledge sources and recipients affects KS outcomes (Argote et al., 2003; Ipe, 2003; Szulanski, 1996; Gupta and Govindarajan, 2000). Thus a supportive firm culture and climate have shown to also play a vital role in individual knowledge sharing behaviour (Huang, et al., 2013). Henceforth, an environment characterised by communication and encouragement to share knowledge is considered important as employees in such environments share and accept willingly rather than forcibly.

Opportunity and intensity of interaction has shown to facilitate knowledge sharing behaviour (Gupta and Govindarajan, 2000), as it reinforces the trustworthiness of the actors. Communication remains an important aspect for the KS process. Within the expatriate context, the opportunity to interact facilitates the development of interpersonal connections and trusting relationships (Oddou et al., 2013; Bonache and Brewster, 2009). Therefore, the more frequent, convenient and rich the opportunities for interaction between expatriates and recipients, the higher the degree of expatriate knowledge sharing (Huang et al., 2013). Similarly during the expatriation process, research findings are indicative of barriers to knowledge sharing relating to lack of contact or infrequent involvement from headquarters or the home subsidiary of the expatriate. Inadequate communication whilst the expatriate are abroad creates a discrepancy in what has been learnt and what the firm learns which naturally leads to a feeling of isolation. This is reflected in Morrison (1993) who found proactive actions such as information seeking from the parent company were more successful in facilitating knowledge sharing compared to reactive, top-down approach. 
The ability and motivation of expatriates and recipients has also been addressed in knowledge sharing post assignment (Argote and Ingram, 2000; Gupta and Govindarajan, 2000; Szulanski, 1996; Minbaeva et al., 2003). Correspondingly, some research affirms the role of the expatriate characteristics on the degree of knowledge shared back to the home subsidiary upon return (Minbaeva, 2007; Minbaeva and Michailova, 2004). Whereas Oddou et al. (2009), accentuate the greater the home unit's orientation toward learning, the higher the probability of repatriate knowledge sharing post assignment (Stroh et al., 20000; Furuya et al., 2009). The trigger for this study was the lack of models that could assist MNCs to better harvest expatriates knowledge acquired overseas.

\subsubsection{Rewards}

Categorised as intrinsic or extrinsic, rewards Cabrera's (2003) research found individuals are more likely to share knowledge if they perceive an individualistic benefit for doing so. Thus, the apparent cost of sharing knowledge is associated with the knowledge sharing of individuals. Extrinsic rewards could only be used for shortterm solutions as once motivation runs out; individuals will revert back to human behaviour. Intrinsic rewards however are in-built behavioural rewards which can motivate for longer periods (Bock, Kim and Yee, 2005) such as recognition, career enhancement and duty of care to the recipient.

Husted and Michailova (2002) argue that knowledge senders' behaviour depends on their inclination to share knowledge on request, as the decision not to share is individual. Although KS is desired from an organisational perspective, the rationale behind withholding knowledge is often justified from the perspective of the sharing individual. The risk of losing unique advantage catalyses a protection mechanism by which the individual withholds knowledge they have a strong feeling of personal ownership (Chang et al., 2012). Under the self-interest assumption, knowledge senders may not be interested in sharing as resources spent could be invested in activities that are more productive for the individual. More importantly, uncertainty of how the knowledge will be received and interpreted is shown to create cautious behaviour, thus not sharing knowledge allows individuals to protect themselves. 
Lastly, individuals may be unwilling to share knowledge for fear of losing a position of privilege and superiority.

\subsubsection{Organisational commitment}

Organisational commitment implies that individuals will think for the overall benefit of the firm due to emotional identification (Cabrera, 2003). KS across MNC units is suggested to increase productivity of employees when they have a positive attitude toward contributing to the firm (Bock et al., 2005). In the case of the expatriate, organisational commitment has a positive relationship with job characteristics and satisfaction (Elanain, 2009). An individual's evaluation of their job and work context supports the role of job characteristics in the KS process. The nature of the expatriate role is highly valuable and carries multiple benefits therefore it is argued that knowledge sharing behaviour is positively related to this. Contrariwise, commitment can be measured by turnover intention following repatriation. Significant proportion of companies generates anaemic returns on expatriate investments (Kjerfve and McLean, 2012). The empiricism clearly showed that expatriates exclusively drove the initiatives taken to share individual knowledge, suggesting that lack of interest in the acquired knowledge, creates expatriate dissatisfaction and reduces efforts of knowledge sharing (Kjerfve and Mclean, 2012). The readiness of the home unit to learn from expatriates as per the characteristics of the recipient is evident (BerthoinAntal and Walker, 2011; Oddou et al., 2013). This implies knowledge does not always reach parts of the home office post as a result of poor communication (Kjerfve and McLean, 2012). Inflexible companies have been thought to hinder themselves in these situations from effective knowledge sharing. The rigidity is controlling and limiting the expatriate from sharing what has been learned.

Antal (2001) also identified barriers that inhibit transformation of individual sharing at the repatriation phase. The Expatriate Career Cycle (ECC) model recognises the prevalent issue of when repatriates return, lack of available positions require having proving worth again. Repatriates note hard times adjusting back to the home organisation, as they often will be placed in positions where their new found knowledge is not be used in the new post, restraining possibilities to share knowledge (Kjerfve and Mclean, 2012). Oddou et al. (2009) therefore rationalised several 
propositions such as greater expertise, ability to develop social networks, re-entry job power and similarity would increase the chances of knowledge sharing as it would enhance the degree of commitment toward the home work unit (Oddou et al., 2009).

\subsection{A New Antecedent}

Conclusively, the studies reviewed state the behaviour of knowledge senders is largely contingent on individual characteristics. Accordingly, the decision to share is driven by two key behavioural factors: the ability and motivation to perform. There is more to gain from increasing the motivation of individuals who are in a higher ability than those who lack. Likewise, there is more to be gained from increasing the ability of expatriates who are highly motivated than those who are not (Antal, 2001). Relevant to the current research, expatriates may not be able to share knowledge as they lack the skills and competencies to do so (Cabrera, 2003). On the other hand, expatriates may have good experience and strong abilities to transfer, but may be unwilling to do so for reasons outlined.

Thus, the current research seeks to address two clear gaps in the expatriate knowledge sharing literature. Firstly, by investigating a new possible antedecedent. Whilst earlier research examins determinants of positive headquarter attention and the role of such on subsidiary outcomes, scholars have recently begun to apply the attention-based view toward the global knoweldge-sourcing process. Based on the assumption of the ability-motivation framework for knowledge sharing, the research finds grounds to argue a strong linkage with the perceived capabilties generated by a higher headquarter attention receiving subsidiary origin and expatriate knowledge sharing. Research has focused on expatriate knowledge sharing within the vertical HQsubsidiary relationship or the repatriation context, as opposed to the most common transition which is from subsidiary to subsidiary. Therefore, this thesis aims to additionally contribute to the limited understanding toward knowledge sharing behaviours of expatriates still in the cycle.

\subsection{Role Of Headquarter Attention in MNC Learning}

Collis, Young and Goold's (2007) definition of corporate headquarters (HQ), 
characterises the responsibility for the whole or most of the MNC. The role of headquarters ability to promote knowledge sharing falls parallel to the traditional view of the MNC organisational learning and is threefold. Headquarters have the required power to make critical operational and strategic decisions, whereas most subsidiaries are viewed as low power actors in comparison. Therefore the role of HQ is distribution of decision-making rights, i.e., defining the overall organisation and establishing unit responsibility (Nell and Ambos, 2013). The second being resource allocation (Ghoshal and Bartlett 1990), as knowledge sharing often requires greater resources in terms of capital, supporting technology, managerial capacity, and specific competence. Finally, the current literature considers the effect of headquarters participation in the KS itself. To extensively iterate the known literature on headquarter attention in the MNC context, the latter discussed roles of headquarters set up the following section of the literature review.

\subsubsection{The Attention Based View of the Firm}

The conventional view of attention is grounded in cognitive psychology research. The human brain for example selects certain information for further interpretation, while ignoring others (Posner and Boies, 1971). Attention in the context of the firm refers to situations that attract HQ focus and consider important at the cognitive level. The inability to pay attention to all the issues suggests the need to be selective (Ocasio, 1997). In recent years, with the introduction of the attention-based view (ABV) of the firm, attention has emerged as a broad construct that includes the noticing, interpreting, and the focusing of time and effort by HQ (Ocasio, 1997; Rerup, 2009). As the objective of the MNC is to maintain competitive advantage, HQ must provide attention to the issues they consider strategically important to the firm (Levy, 2005; Bouquet and Birkinshaw, 2009). Correspondingly, the ABV postulates the behaviour of an organisation therefore depends on how headquarters distribute and sustain their attention towards, in this case, subsidiaries (Ocasio, 1997).

Ocasio (1997) finds three inter-related premises of the ABV, which explain the HQ attention decisions and how these impact subsidiary behaviour. Firstly, focus of attention refers to HQ focusing attention on a selected set of issues. The outcome of which, suggested to be reflected by the decisions made by the subsidiary 
itself. Secondly, situated attention refers to attention selection, which is context dependent on the location of HQ. Through their participation in procedural and communication channels, HQ are likely to shift attention over time as they interact with multiple subsidiaries, each with its own set of issues considered vital for the MNC. Lastly, structural distribution of attention implies the contexts in which headquarters are present is determined by company strategy (Bouquet and Birkinshaw, 2009). Prior research has since described subsidiary-headquarters relationships as a mixed-motive dyad, where both parties attempt to optimise their own agenda while contributing to the organisational effectiveness (Ghoshal and Nohria 1989).

\subsubsection{Headquarters Attention to the subsidiary}

The research follow Bouquet and Birkinshaw (2008) definition of headquarter attention as "the extent to which the parent company recognises and gives credit to the subsidiary for its contribution to the MNC as a whole". In the context of the modern MNC the allocation of headquarters' attention to subsidiary units has arguably become a key strategic issue (Campbell 1989; Bouquet and Birkinshaw 2008; Birkinshaw et al., 2007). Some scholars argue it to be the most critical, scarce and sought-after resource (Hansen and Haas 2001; Bouquet and Birkinshaw 2008). The thesis also acknowledges recently presented negative manifestations of headquarters' attention, which are difficult to differentiate from control or monitoring (Bouquet and Birkinshaw 2008). For the sake of conceptual clarity, in this thesis, we refer only to the positive aspects of attention as per (Bouquet and Birkinshaw 2008) where an empirically validated construct exists. We view HQ attention as a multidimensional construct whereby a lack of any single dimension will decrease but not totally eliminate the positive attention granted to a subsidiary.

Ocasio (2011) acknowledges three different types of attention: attention perspective, attention engagement, and attention selection. Accordingly, subsidiaries create varying perceptions of these attention forms, as they exist at different levels. At the strategic level lies attention perspective; attention engagement however refers to the operational aspects such as the routine of headquarters to devote their attention to specific business opportunities. These different attention forms will be discussed in 
the following sub-sections as it is worth mentioning the many similarities these concepts have to others used in the literature.

Table 1. Comparison between Attention Concepts

\begin{tabular}{|c|c|}
\hline Types of Attention & $\begin{array}{l}\text { Comparable Concepts in Attention } \\
\text { Literature }\end{array}$ \\
\hline Attention Selection & $\begin{array}{l}\text { Focus of attention: Decision by headquarters } \\
\text { to devote their attention to a particular set of } \\
\text { issues (or subsidiaries for this thesis) } \\
\text { (Kahneman, 1973; Ocasio, 1997). }\end{array}$ \\
\hline Attention Perspective & $\begin{array}{l}\text { Cognitive attention: Reflects the issues that } \\
\text { headquarters view as important based on } \\
\text { their cognitive knowledge (Posner and } \\
\text { Boies, 1971) } \\
\text { Visible attention: Recognition given to the } \\
\text { subsidiaries by the headquarters through the } \\
\text { external modes of communication used for } \\
\text { conveying information about strategy, future } \\
\text { planning, and performance to shareholders } \\
\text { (e.g. annual reports, videos) (Bouquet and } \\
\text { Birkinshaw, 2008) } \\
\text { Relative attention: Assessment of strategic } \\
\text { importance of a subsidiary in comparison to } \\
\text { other subsidiaries in the MNC. This is based } \\
\text { on the level of recognition and credit they } \\
\text { receive from the headquarters (Bouquet and } \\
\text { Birkinshaw, 2008) }\end{array}$ \\
\hline Attention Engagement & $\begin{array}{l}\text { Structural attention: The issues that } \\
\text { headquarters recognise as important based } \\
\text { on their cognitive knowledge. This is shaped } \\
\text { by the structures through which they obtain }\end{array}$ \\
\hline
\end{tabular}




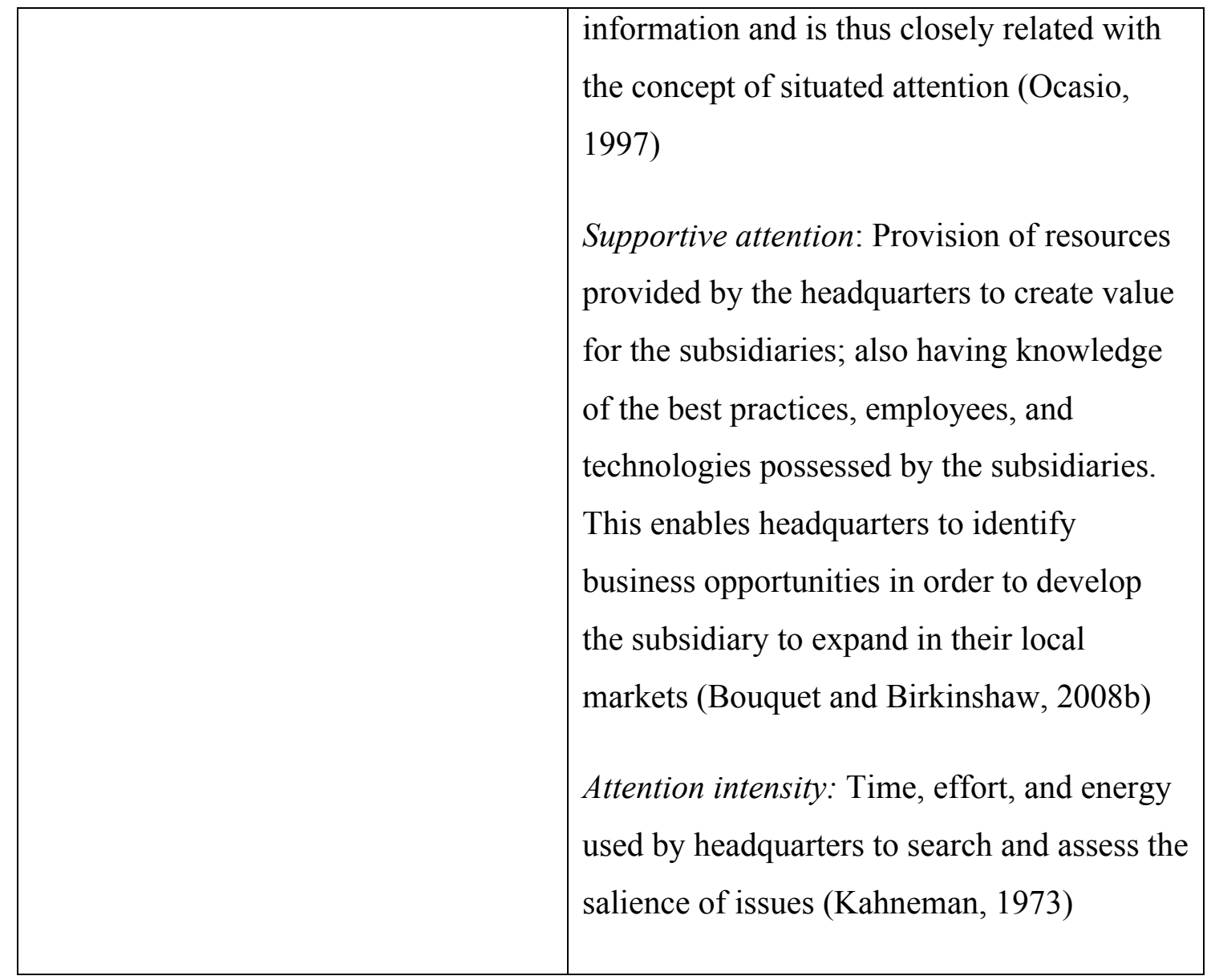

\subsubsection{Perception of Attention Selection}

The role of cognitive factors has largely gone amiss as literature reflects more on the mechanistic relationships between headquarters and subsidiaries. Attention selection refers to the specific issues headquarter chooses to focus at the expense of other issues (Ocasio, 1997). This form of attention is general a byproduct of the interplay between attention perspective and attention engagement however in normal scenarios all three types of attention align with one another (Elsbach et al., 2005). Different actors have diverging opinions of how attention should be allocated creating a non-trivial matching problem within the literature. Subsidiaries draw on HQ attention selection to consequently make assumptions about the other two types of attention. In earlier attention research, findings show that subsidiaries will comply with the strategic decisions of HQ when the subsidiary understands the process through which these decisions are made as fair (Kim and Mauborgne, 1993). Likewise, the interpretation through which subsidiaries engage in making sense of attention decisions are linked 
to the subsidiary's overall motivation for sharing opportunities or communicating other knowledge with the headquarters through procedural channels.

\subsubsection{Perception of Attention Perspective}

Attention perspective recognises the cognitive dimension of attention without linking it to the structural aspects originally presented in the ABV (Ocasio, 1997, 2011). Attention perspective aligns with corporate strategy, allowing headquarters' to cognitively assess how attention should be distributed across subsidiaries and the business opportunities within. This distribution hinges on the existing cognitive knowledge of headquarters based on past evaluations and desired future prospects of the firm (Gavetti and Levinthal, 2000). Subsidiary strategic configurations identify the different roles subsidiaries play in the MNC network including, autonomy, power, or entrepreneurial orientation (Bartlett and Ghoshal 1989; Gupta and Govindarajan 1991; Birkinshaw and Morrisson 1995; Paterson and Brock 2002). Subsidiary weight refers to the power a subsidiary has in the $\mathrm{MNC}$, which can reduce the power asymmetry evident in the traditional relationship with HQ, influencing attention in the process (Bouquet and Birkinshaw, 2008; Dörrenbächer and Gammelgaard, 2016). Weight can also be a result of the functional role assigned by the headquarters (Forsgren, Holm, and Johanson, 2005). Subsidiaries with weight are shown to strive for headquarter attention to maximise performance and legitimise themselves whilst securing resources and support to seize local opportunities (Bouquet and Birkinshaw, 2009). Accordingly, subsidiaries' dependence on voice is based on weight and possession of contextual knowledge regarding the headquarters and MNC (Dörrenbächer and Gammelgaard, 2016; Dutton et al., 2001). HQ grants attention to these subsidiaries due to the reliance on certain opportunities to utilise host-country specific knowledge (Luo 2003). Consequently, these subsidiaries have bargaining power over other actors to possess critical resources (Birkinshaw 1997). In sum, strategic configurations determine how subsidiaries are able to leverage resources and may be used to describe the headquarters-subsidiary relationship and set contingencies for their interaction. The entwined concept of relative attention therefore acknowledges the perceived level of recognition given to a focal subsidiary relative to others. 
Accordingly, other subsidiaries are in the position to assess their strategic importance through their perception of the attention perspective of the headquarters. This information can be obtained via the mediums that firms use to communicate company strategy to employees of the organisation (e.g. newsletters, CEO videos, podcasts) and external shareholders such annual reports. This is especially true when these subsidiaries are not part of strategy formulation directly (Plourde et al., 2014). As such, the assessment of strategic importance is related to the subsidiary motivation to communicate with headquarters and actively participate in the procedural and communication channels within the firm. In this context, the level of attention received from headquarters constitutes an important indicator whether global leverage is achievable. Based on perception of attention perspective, subsidiaries that feel they lack strategic importance may hesitate to utilise communication channels to share initiatives with the headquarters, as they believe their voice would be unable to attract the headquarters' attention (Morrison, 2014). Naturally, this implies that attention to one subsidiary automatically means less attention to others, which therefore act as a mechanism of subsidiary development over time. For the purpose of this research this particular factor is of relevance when applied to the context of the expatriate.

\subsubsection{Perception of Attention Engagement}

Attention engagement is defined as the "process of intentional, sustained allocation of cognitive resources to guide problem solving, planning, sense-making, and decision making" (Ocasio, 2011, p. 1288). It relates to the actual time, effort, and energy exerted by HQ to obtain information, evaluate, and prepare responses to different issues facing the subsidiary (Ocasio, 1997). Another similar term used in the academic literature to refer to this is supportive attention whereby it captures the provision of discretionary resources by the corporate parent to facilitate the subsidiary's development (Bouquet and Birkinshaw, 2009).

Consistent with the $\mathrm{ABV}$, attention engagement is grounded on the view that $\mathrm{HQ}$ cognitive knowledge is associated to procedural and communication channels. This contrast to the perspective of attention, which solely focus on attention outcomes derived from the cognitive level. In MNC context, the attention engagement of headquarters relates to their partaking in the channels subsidiaries are also present. 
Ocasio (2011) further asserts that attention engagement has two imperative supporting components i.e. vigilance and executive attention. Vigilance (Rerup, 2009) enables headquarters to maintain their attention on a particular stimulus over time without interruption. Executive attention provides flexibility for headquarters to shift their attention across different subsidiaries, therefore offering the opportunity to devote attention to particular subsidiaries when necessary and move away when other subsidiaries demand more attention. Balancing the two forms of attention engagement can address the challenge raised by Rerup (2009) of ensuring consistency and diversity of attention.

Subsidiary perception of HQ attention engagement outlines a sense of how the headquarters act upon their strategic intentions. This relates to how the subsidiaries feel about their level of participation in procedural and communication channels and more importantly, the perceived level of knowledge possessed by headquarters about their specific subsidiary unit and the markets (Ocasio, 2011). The literature implies positive perceptions of this form of attention not only enables subsidiary motivation but also will moderate the outcome of active subsidiary participation. For example, regular visits from headquarter management or even the CEO enable the likelihood of communicating business opportunities through real-time meetings. As does it enable subsidiary confidence when communicating informally with the headquarters. It is even possible to receive more attention engagement in certain circumstances due to a strong personal relationship with or close proximity to the headquarters, both in terms of cultural and geographic distance (Denrell et al., 2004; Monteiro et al., 2008; Bouquet et al., 2009; Ocasio and Joseph, 2005).

\subsubsection{Effect of HQ Attention on Knowledge Sharing}

For the sake of conceptual clarity this thesis draws on positive aspects of HQ attention across visible, supportive and relative aspects (Bouquet and Birkinshaw 2008) where an empirically validated construct exists. To mitigate knowledge deficit, HQ attempt to value create by encouraging knowledge sharing among peer subsidiaries (Bouquet and Birkinshaw, 2008; Verbeke et al., 2013). The current research appears to only suggest the role of HQ attention in knowledge sharing as associated with heightened control (Bjorkman, Barner-Rasmussen, and Li, 2004) therefore effective sharing of 
knowledge at the subsidiary level depends on headquarters ability to influence learning in and among subunits throughout MNCs. Intra-MNC social capital is resources derived from the relationships between subsidiary-HQ and subsidiarysubsidiaries. Formal and informal MNC socialisation is a key factor affecting the extent to which knowledge sharing occurs (Wang and Yang, 2007). As presented in review of MNC knowledge flows, the current thesis seeks to contribute to the understanding of knowledge flows in subsidiary-subsidiary social capital. In order for this to be examined, the thesis also draws on the ABV to highlight the HQ-subsidiary relationship (vertical socialisation). Arguably, the research known on headquarter attention demonstrates that more attention from headquarters provides subsidiaries with necessary contextual knowledge to make strategically enhanced decisions when exploring new business opportunities (Ciabuschi, Martin and Stahl, 2010). Hence, frequent communication and attention received by headquarters enables subsidiaries to gain unique knowledge about the headquarters and the organisation in general to develop enhanced knowledge.

Theoretically, the MNC is only able to exploit diverse market presence when HQ provides opportunities for subsidiaries to actively participate in knowledge sharing activities. However this is only attainable when subsidiaries are motivated but also in a position to use weight and voice to divert headquarter attention, however this is a known challenge as headquarter attention is not distributed equally. Resultantly, HQ can only devote set amounts of attention to selected information shared by subsidiaries and furthermore, some subsidiaries are likely to receive a relatively high level of attention while others are likely to be completely ignored, thus impacting subsidiaries' motivation to engage with HQ. Based on the above summary of ABV research, the subsidiary perspective shows it to be difficult to believe headquarters distribution of attention as fair. However, where attention selection is perceived as unbiased, and the perception that it is relatively easy to get a message across to the headquarters, subsidiaries will be motivated to engage in procedural and communication channels with HQ to share insight more openly.

Only recently have authors begun taking the first steps to reveal the impact of HQ atention on the headquarters-subsidiary relationship (Haas and Hansen. 2001; Bouquet and Birkinshaw, 2008). In its essence, we observe HQ attention as a positive 
resource derived from HQ-subsidiary relationships. Whilst a large stream of HQ attention research has examined the factors shaping distribution and scanning of the strategic environment (Sharma, 2000), little is known on how these affect subsidiary actions such as knowledge sharing (Garg et al., 2003). Although limited literature surrounds headquarter attention and knowledge flows, it has been speculated that attention decisions are likely to impact subsidiary motivation to engage in knowledge sharing behaviour as it provides a sense of their importance or value in the MNC (Kim and Mauborgne, 1993).

\subsection{Effect of HQ Attention on Expatriate Knowledge Sharing}

Known linkages between headquarter attention and the expatriates are as follows. HQ attention literature has shown that attention is affected by both internal and external stimuli (Birkinshaw, Bouquet, and Ambos, 2007; Bouquet and Birkinshaw, 2008, 2009). From this, scholars gathered that attention becomes established through reflective structures of the priorities of the $\mathrm{MNC}$, favouring subsidiaries within markets identified as important (Bouquet and Birkinshaw, 2009). The expatriate therefore has a critical role in capturing headquarters' attention toward knowledge that would otherwise have been ignored (Plourde et al., 2014). Similarly, Monteiro (2015) explored the circumstances under which expatriates can help capture HQ attention for a subsidiary. It can be assumed that in situations where the market of the subsidiary is showing signs of growth, the expatriate is able to signal opportunities to HQ (Plourde et al., 2014) utilising reverse knowledge flows. The ability for expatriates to share knowledge back to the headquarters is largely attributed to their experience at both headquarters and in the current host-subsidiary. From the perspective of the subsidiary, expatriates enjoy greater access to headquarters employees than host-country employees.

\subsection{Theoretical Gap}

The key argument explored in this thesis amalgamates gaps spanning the different research streams. Firstly, conceptualisations of knowledge flows recognise knowledge benefit subsidiaries receive from not only HQ but also other units that have access by virtue of being in a certain location. Thus MNC learning is a multidirectional flow of 
knowledge and the thesis addresses the call to examine lateral subsidiary-tosubsidiary knowledge sharing more in-depth by examining expatriates moving across assignments.

Accordingly, we find across the knowledge management, expatriate and ABV literature, theorisations that certain context and players of enhanced or differentiated knowledge stocks are beneficial for other units in the MNC that would not have the same access. Subsidiaries receiving high levels of headquarter attention may be considered such a context. As per the ABV, HQ attention allocation is unequally distributed. Given the significance of this outcome, the thesis finds a surprising dearth of effort conceptualising relative HQ attention or HQ attention disparity as its own construct in the ABV literature. Nor is there a strong understanding on the significance HQ attention disparity may hold in different contexts. Consequently, the impact of HQ attention disparities on subsidiary outcomes is limited, as is research done on individuals receiving attention from the headquarters; labeled as 'attention carriers' (Occasio, 2011). This thesis seeks to integrate knowledge management and attention based view research by addressing the proposed gaps under a new context. 


\section{CHAPTER THREE: METHODOLOGY}

The following chapter provides an outline of the research methodology used to collect and analyse the data in addressing the current study. This chapter begins with a discussion of the implemented research design, followed by a review of the tailored data collection process and analysis. The section concludes with the role of the researcher and addresses potential bias and also includes information of participant profiles with ethical considerations.

\subsection{Research Philosophy}

The Greek term hermeneutics refers to the interpretation of written word, seeking to identify conditions under which human actions take place (Cohen et al., 2016). It is a scientific tradition, existing in both qualitative and quantitative studies; however commonly applied to qualitative approaches, as interpretations are essential (Gummesson, 2003; Thomas, 2006). Individuals tend to encounter unique experiences, therefore research concerning people is difficult to generalise. The study aligns with hermeneutics in the way that the individual's perception of HQ attention disparity is important. Described as the interpretive process to understand the subjective nature of that experience, hermeneutics is positioned as a suitable research perspective for the current study (Tan, Wilson and Olver., 2009).

Hermeneutical research considers pre-understanding; understanding and explanation of respondent interpretation as essential (Gummesson, 2003). As the thsis seeks to add to the existing knowledge management and headquarter attention literature there must be a base understanding spanning these research streams in order to analyse expatriate perceptions of headquarter attention disparities. These will later uncover the prevalent mechanisms, which link these disparities to expatriate knowledge sharing. This stresses the need to have a pre-understanding of the research topic. The nature of their knowledge sharing under these circumstances might be ambiguous and transient to its nature and therefore an explanation from a hermeneutical viewpoint is more appropriate for this study. 


\subsection{Research Approach}

In the field of knowledge sharing, research has predominately utilised quantitative methods to measure knowledge from a numerical perspective, focusing on the microelements whereas expatriate research tends to follow a mixed avenue. As the role of HQ attention disparity is yet to be fully explored, the interviews seek to add expatriate voices to the existing qualitative research to generate deeper understandings.

Whilst quantitative research is fundamentally built on numerical analysis in large samples, qualitative research focuses on exploration of text derived from smaller samples (Patton, 1990). Notably, the subjects of study are people and collected from a narrow population, thus the qualitative approach seemed suitable for our purpose. This can add to future research by which quantitative measures can be derived. Three central aspects characterise qualitative research: ability to interpret reality from the respondent's perspective; ability to study the relationship between theory and research; ability to generalise the results derived from qualitative research (Bryman, 2001). The research seeks to add to the knowledge sharing phenomena with specific focus on the impact of the attention-based view of the firm hence asking a combination of "how" and "why" questions to explain the relationship. The ability for a researcher to gain awareness from the patterns presented in the data justifies the appropriateness of qualitative research (Maxwell, 2012).

An abductive approach was used, bouncing "back and forth" between existing conceptualisations and observations to increase the understanding of theory and findings (Dubois and Gadde, 2002). The research is based on existing theories, with relation to knowledge sharing, attention-based view of the firm and social capital. This was fundamental toward acknowledging current contributions and investigating unexplored antecedents within the knowledge sharing process. Evidently, this abductive approach meant for an in-depth revision of the final theoretical framework. Given the little attention of this angle in both prior quantitative and qualitative studies, the proposed qualitative semi-structured interview was selected as an appropriate data collection method (Saunders et al., 2009). 


\subsubsection{Use of In-Depth Semi-Structured Interviews}

Studies using in-depth semi-structured interviews seek to uncover structure and logic through systematic presentations of interview descriptions (Leech, 2002). Semistructured interviews have been chosen to provide an appropriate level of flexibility in the interview process, allowing points of interest to be followed up and re-ordering of questions if it becomes contextually appropriate to do so, stimulating responses of detailed narratives and descriptions (DiCicco-Bloom \& Crabtree, 2006). They also allow subsequent analysis to identify themes and use of dialogue that would be more limited in interviews with stricter structures, allowing more accurate identification of personal values and expression of "experiential data" (Leech, 2002). Thus, semistructured interviews were the chosen to allow the researcher to participate in the research process to ensure the descriptive shared is reflective of their reality (Denzin and Lincoln, 2011).

\subsection{The Interview Process}

Following DiCicco-Bloom and Crabtree's (2006) key features of semi-structured interviews, the researcher implemented an interview process, which encompassed the following elements:

- Scheduled in advance

- Located outside every day events such as work

- Prepared around a predetermined interview guideline

- Probe questions generated from the narrative of the participant

- Last typically between 30 minutes to several hours

The interview guide consisted of 12 open-ended questions. This gave the researcher freedom to probe respondents' experiences and feelings thus enhancing the richness and quality of the raw data (Bryman, 2001; Leech, 2002). To generate quality information, the interviews lasted between 40 minutes to an hour. 


\subsubsection{Case Selection}

Case studies become appropriate when seeking to gain further insight into the phenomenon of antecedents in expatriate knowledge sharing (Castañeda and Ignacio, 2015). This thesis is considered novel with respect to knowledge sharing having not yet been theoretically linked against headquarter attention. The research maintains that using case studies can accomplish theory generation as we aim to extend the knowledge-sharing model. The research undertook 18 interviews deemed sizeable enough to attain 'data saturation' (Fusch and Ness, 2015) as the purpose of the interviews were dedicated to obtaining quality data. Some expatriates abroad had limited time, which further justifies conducting more interviews to focus on quality across multiple cases.

Sampling strategies will be summarised meticulously for interpretation and replication. The researcher used two types of purposeful sampling: selective sampling and snowball sampling. The intention of purposeful sampling is that the "logic and power of purposeful sampling lies in the selecting information-rich cases for study in depth. Information-rich cases are those from which one can learn a great deal about issues of central importance to the purpose of the research, thus the term purposeful sampling" (Patton, 1990 p. 169). The interviewed expatriates reflect individuals who are reflective, articulate and most importantly, willing to share what they have experienced with the interviewer.

\subsubsection{Participant Recruitment}

Participant recruitment methods were twofold: online advertisement posting on expatriate forums such as the InterNations LinkedIn page and reaching out to family and friends. Selective sampling chose the first five participants based on interest generated online according to a reasonable initial set of criteria. For example, the research required the experience to have occurred no more than 5 years ago however this was challenging to achieve within the limited pool of participants and timeframe. 
A sizeable portion of interviewees was resultant of snowball sampling in conjunction with selective sampling. Leech and Onwuegbuzie (2007) note that snowball sampling requires participants from initial recruitment to identify subsequent participants who they deemed appropriate in terms of the selection criteria. This process occurred after the first 5 interviews where participants emailed the researcher candidate referrals. This was applied across each recruitment method till the point of saturation. On one occasion, the researcher established rapport with a senior expatriate coordinator through LinkedIn for Company $\mathrm{F}$ who was initiated an email to referred candidates and left it up to the researcher to follow up.

Responsive candidates were contacted through email and presented with an introduction to the study, criteria and an information sheet as shown in Appendix After confirming criteria alignment, the location of the interview was arranged. These varied from face-to-face interviews to Skype interviews. Although participants had the autonomy to choose where and when was most convenient to them, the location in question had to be private and quiet. Two days before the arranged time, the researcher contacted participants once again to reiterate the research purpose alongside topics that would be covered. Participants interviewed through Skype were provided with an information sheet and consent form to review and sign one to two days prior whereas, participants during real time interviews were presented with the forms on the day.

\subsubsection{Participant Characteristics}

Expatriate knowledge sharing is becoming a focus of corporate concern due to weak knowledge extraction. Business expatriates are considered the frontline of many MNC operations abroad therefore are familiar with the importance of effective knowledge flows (Antal, 2001). The research adopts the perspective of the expatriate to reflect the experiences of the knowledge sender and gain novel perceptions linking the role of headquarter attention. Accordingly, we theorise knowledge sharing across subsidiaries to involve a knowledge sender and knowledge recipient, the success of which can be attributed to various determinants, some of which may still not be known. 
Participants consisted of adult expatriates who had to fit the following criteria in order to qualify: 1) Worked for two different subsidiaries of the same multinational 2) Spent a minimum of 6 months in each subsidiary to adequately reflect on both the environment and behaviours 3) Willingness to share in-depth experiences. Appropriate interview lengths allows for thorough sharing of experiences and to be articulate enough to convey details. Names of participants will be replaced to entice deeper experiential sharing by building a sense of security. Company names will also not be used for this reason. Nine companies in total were interviewed across several different industries. Majority of the interviewees possessed mid-level manager authority across both assignments with the few exceptions of specialists or senior management.

Table 2: Company Characteristics

\begin{tabular}{|c|l|c|c|}
\hline COMPANY & \multicolumn{1}{|c|}{ INDUSTRY } & HQ LOCATION & INTERVIEWEES \\
\hline A & $\begin{array}{l}\text { Electronics \& Home } \\
\text { Appliance }\end{array}$ & Netherlands & A1 \\
\hline B & Professional Services & London & B2 \\
\hline C & Food processing & Switzerland & C3 \\
\hline D & Tobacco & United Kingdom \& & D4 \\
\hline E & Conglomerate & USA & E5 \\
\hline F & Primary Producer & New Zealand & F6-15 \\
\hline G & Professional Services & Ireland & G16 \\
\hline H & Software & USA & H17 \\
\hline I & Food processing & UK & I18 \\
\hline
\end{tabular}

Table 3: Participant Characteristics

\begin{tabular}{|l|c|c|c|}
\hline Gender & Percentage & Age & Percentage \\
\hline Female & $22.2 \%$ & Under 39 & $22.2 \%$ \\
\hline
\end{tabular}




\begin{tabular}{|l|l|l|l|}
\hline Male & $77.8 \%$ & 39 or over & $77.8 \%$ \\
\hline
\end{tabular}

Table 4: Assignment Characteristics

\begin{tabular}{|l|c|c|c|}
\hline $\begin{array}{l}\text { Perceived attention } \\
\text { transition }\end{array}$ & Percentage & $\begin{array}{l}\text { Function similarity } \\
\text { across assignments }\end{array}$ & Percentage \\
\hline High to low & $27 \%$ & Yes & $55 \%$ \\
\hline Low to high & $55 \%$ & No & $44 \%$ \\
\hline Equal & $16 \%$ & & \\
\hline
\end{tabular}

\subsection{The Interview}

All interviews were recorded on the researchers phone then transcribed on the same day. Based on Whiting (2008) reporting's of participants feeling inhibited by the presence of a recording tape, using a phone as a discreet recording device created a more comfortable atmosphere. The researcher would occasionally pause to verify their interpretation of what interviewees said (Thomas, 2006). The structure of the interview followed DiCicco-Bloom and Crabtree's (2006) four phases of an interview: apprehension, exploration, co-operation and participation. The multiple phases' ensured rapport and a trusting relationship were built between the interviewer and the participants in order to facilitate detailed free flowing conversation (DiCiccoBloom and Crabtree, 2006).

The apprehension stage involved the researcher and participant engaging in conversation regarding their overall experience on order to facilitate a relaxed environment, evading common feelings of uncertainty (DiCicco-Bloom and Crabtree, 2006). The semi-structured nature enabled broad open-ended questions to create a consistent flow and ensure that key ideas are being addressed (Whiting, 2008). These broad answers were followed up by prompts and clarifications to help shape the experiences, feelings and opinions which participants may reply to vaguely otherwise (Whiting, 2008). Participants engaged in more insightful descriptions during the exploration phase (DiCicco-Bloom and Crabtree, 2006). Asking open-ended questions encouraged participants to identify their own perceptions and reflect on their identity as expatriates. The co-operative phase allowed for more thought- 
provoking questions (Whiting, 2008). For example, participants were asked to describe their perception of the importance of their first subsidiary. Answers broadly went to include market size, share and strategic importance of the market. The researcher then prompted participants to explain how this was reflected through headquarters behaviour. The participation phase is where the greatest level of rapport is developed between researcher and participant according to DiCicco-Bloom and Crabtree, (2006). In order for this phase to be reached, the interview itself had to be flowing for a certain amount of time as shorter interview's can hinder this process (Whiting, 2008).

Conclusion is achieved when the researcher believes to have met data saturation. The researcher concluded the interview by giving thanks for their time. Gifts were not deemed appropriate for this research due to location restraints. However, this is supported by Whiting's research, which emphasises that it is important for researchers to be aware that gifts should not provide incentives thus giving rise to accusations of bias. The researcher transcribed the interviews. Outlined in the consent sheet, participants were given the option to review the transcript to ensure the interview was captured accurately.

\subsection{Data Analysis}

Thematic analysis was used in the research, being a method for identifying, analysing and reporting patterns within data and minimally organizes and describes the data set in rich detail (Boyatzis, 1998). This form of analysis differs from other tools as it seeks to assess psychological components of subjects, such as perceptions and personal understanding (Dittmar \& Drury, 2000). Braun and Clarke (2006) define a theme as capturing an important part across the data set in relation to the research objectives. The process of analysing the interviews involved arranging the data to identify patterns in semantic content, summarising and then interpreting the data set. The research used the aid of qualitative analysis software, NVivo (version 11). The following sections will outline key steps undertaken by the researcher when conducting theoretical thematic analysis, which is based on the work and findings of Braun and Clarke (2006). Encompassed within this procedure, fundamental manipulation operations: categorisation, abstraction, comparison and integration as 
per the work of Spiggle (1994) were utilised to stretch the data interpretation and construct a coherent conceptual explanation.

The researcher firstly familiarised herself with the data. Transcribing interviews is an essential part of this, but the researcher was also immersed in the data set by repeatedly reading over the transcripts in conjunction with the audio file playing to ensure accuracy and until the researcher became familiar with the depth and breadth of the content (Braun \& Clarke, 2006).

Phase two of the process was the sending of transcripts to relevant participants for them to read over their responses. Member checks are crucial when ensuring the data's trustworthiness (Lincoln \& Guba, 1985) and the participants were given the opportunity to make changes if necessary. The transcripts were then uploaded into NVivo for step three.

In phase four, the researcher created initial codes by identifying content that was relevant to the research question and overall research objectives. These code structures were then entered into NVivo. Initial codes are critical as they contribute to the base of the thematic analysis (Welch and Piekkari, 2006).

Step five involved categorisation upon coding the transcripts. The researcher followed a systematic approach during coding in an effort to give a full and equal amount of attention to each transcript. As the researcher coded, notes on the participants such as similarities and discrepancies between interviewees based on key opinions were thoroughly documented. Categorisation was achieved by identifying a section of data that represented or belonged to a general phenomenon related to the research and then assigning it to new or existing codes achieved the concept of categorisation.

In step six, the researcher undertook an iterative process to study the codes using abstraction. Abstraction further established categorisation, as it categorised prior categories into more general sub themes and main themes, otherwise known as conceptual classifications. The researcher also generated visual maps outside of NVivo of main conceptual classifications to support the identification process. 
Step seven involved doing comparisons between codes. Comparison allowed the researcher to investigate the similarities and disparities across cases within the data. Each incident within a case is compared to other incidents within the same category. As the analysis progressed, categories and themes were refined so that they formed "coherent patterns" and the "validity of individual themes" is considered (Braun \& Clarke, 2006, p. 91). This step also involved coding extra data that the researcher may have looked over in earlier steps and recoding the already established themes. The researcher expected to recode as it is an "ongoing organic process" (Braun \& Clarke, 2006, p. 91). Next, the researcher defined themes and gave them titles. This also meant the visual maps created earlier needed to be refined, and the researcher needed to clarify whether the themes showed evidence of sub themes.

Throughout the data analysis process, the researcher applied iteration which means to move back forth between stages as opposed to implementing research states in a strict consecutive order (Spiggle, 1994). Upon analysing each separate interview, the researcher generated main themes and then went to review the interview again. The back and forth motion occurred between each interview as a separate par and the set of interviews as a whole. Similarly, when analysing a single interview, the iteration process was between distinctive passages within the interview and the interview overall. Iteration aids abductive research by allowing the development of emerging themes/categories/conceptual relationships for further exploration (Dubois and Gadde, 2002). It also authorises a more strengthened and unified interpretation of the data. Concluding this entire process, the researcher reported her findings and discussion to narrate what Braun and Clarke (2006, p. 93) consider the "complicated story of data". The researcher did this in such a way that the process and findings could be understood in a comprehensible way, so the validity of the research is not compromised.

\subsection{Trustworthiness and Validity}

When seeking to evaluate trustworthiness and authenticity, the present research was planned and assessed based on the framework provided by Denzin and Lincoln (2011), who highlight the necessity of credibility, transferability, dependability, conformability and authenticity. Credibility contributes to a belief in the 
trustworthiness of the data and refers to accurate interpretation and representation of the participants' views (Graneheim and Lundman, 2004). This study applied some of the suggested techniques that increase the chances of producing credible findings. These techniques include, prolonged engagement and member checks (Schwandt, Lincoln, \& Guba, 2007). The lengthy interaction of the in-depth semi-structured interviews enabled the researcher to prolong the engagement between participant and researcher. This facilitated a building of trust between both parties and also allowed the researcher to be more in tune with the participant's reality. This is to insure the credibility of the data and vital from a constructivist standpoint (Patton, 1999).

\subsubsection{Researcher Role and Bias}

Bracketing allowed the researcher to become aware of biases she may hold concerning the research. The bracketing process included hypothetically answering the interview guideline based on the same participant protocol. The awareness of bias implied making conscious effort in avoiding misguidance of topics during the interview. It must still be recognised that whilst the research made diligent efforts in avoiding personal biases, the exclusion of such cannot be guaranteed. The use of thematic analysis for example is evidently subject to the researcher's interpretation.

\subsection{Ethical Considerations}

This thesis was completed in accordance with the guidelines of the Human Ethics Committee of Victoria University of Wellington. Ethical approval was obtained prior to conducting research in order to maintain the integrity of the research and reputation of the academic institution. Participants were informed both verbally and in writing that they could withdraw from the study at any time and that their names, company and responses would be strictly confidential with pseudonyms. Participants were also informed that data gathered as part of the process will be stored with the researcher for a period of 3 years after which all data would be destroyed. Consent was given prior to the interviews to protect both participants and researcher. This study did not have any significant ethical or privacy risks due to full anonymity. 


\section{CHAPTER FOUR: FINDINGS}

The following chapter analyses key findings of the research using thematic analysis. It can be generalised that interviewees are aware the weight knowledge sharing carries in their respective MNCs, the majority claiming to have shared knowledge in some shape or form. However, in light of the research question, the findings highlight variance regarding the level of knowledge expatriates' felt able or motivated to share across assignments in certain situations and under particular conditions resultant of headquarter attention levels.

The researcher presents the qualitative findings as themes, beginning with evidence supporting HQ attention disparities between subsidiary assignments exist. This was considered a prerequisite for the study. Perceptions concerning the value and/or benefit of knowledge respective to each subsidiary the expatriate moves across are shown to be the key mechanism linking the two research variables. This is explored through two perspectives, namely: expatriate perception of knowledge and the host subsidiary [S2] perception of knowledge. Each theme discusses their role in influencing expatriates to share knowledge as per the ability-motivation framework (Argote et al., 2003). Some themes require analysing the impact of knowledge at subsidiary level before relating the observed outcomes to the expatriate, whereas others directly relate to the expatriate. The findings also integrate three external variables: socialisation, functional relevance and subsidiary perception of fairness that were shown to alter the relationship between the proposed mechanism and the expatriate's KS. Thereafter, a conceptual framework is presented to illustrate these findings, which underpin the two-dimensional perspectives.

\subsection{Disparities in HQ Attention}

The data confirms there indeed exist marked differences in the level of HQ attention some subsidiaries receive relative to another. It transpires that the expatriate can move from a higher-attention receiving subsidiary to a less-attention receiving subsidiary, vice versa or both subsidiaries are considered "equal". Suggestive of the literature, the findings imply this is a common occurrence across multiple industries. 
Unsurprisingly, "hot market" subsidiaries tend to receive the most attention from headquarters across all aspects, including resources, investment and communication across various mediums. This is suggested to occur in subsidiaries that HQ expect exponential growth potential, or consider successful markets the HQ can continue to develop. Presumably, this research confirms the natural inclination for headquarters to pay more attention to these subsidiaries. HQAD is thus contingent on the strategic importance of the subsidiary for the MNC.

Contrastingly, the findings also suggest to a lesser extent, HQ granting high performing subsidiaries with autonomy whereas underperforming subsidiaries faced the brunt of the attention. Nonetheless, interviewees acknowledge HQAD occurs. This particular finding alerted the study to acknowledge emerging ABV literature highlighting that attention is slowly being considered as a multifaceted phenomenon. Not all attention is necessarily positive as traditionalists in the field depict. For the purpose of the current research however, we continue to follow the works of Bouquet and Birkinshaw (2009) and refer attention to headquarter actions spanning across visible, supportive and relative aspects. Illustrated below is evidence to suggest the proposed disparity exists, interviewees highlighting a clear association between prioritised subsidiaries and abundance of HQ attention:

...in Indonesia we got heaps of supplies from $H Q$ and we were treated a little bit differently where is in Dubai we kind of got last of whatever allocation was available to us so you definitely noticed through some physical parts there-

\section{Interviewee F6}

... [HQ] priority goes to the top markets...so that is where the attention goes... - Interviewee F12

In support of the findings above, Interviewee F6 and F12's opinions were convergent with interviewees who spoke of their observations when operating in a low-attention subsidiary. What the findings established was that the perception of HQ engagement attention evidently shaped the outcome of the subsidiaries voice. This meant that for expatriates who considered a subsidiary as not receiving regular interaction with HQ relative to another, they encounter stronger challenges in trying to adopt initiative- 
taking approaches to gain a central position in the MNC. Accordingly, the study findings suggest that subsidiary voice is only beneficial in generating HQ attention with it is used in conjunction with substantial weight to attract HQ attention and influence decisions. As a consequence, the findings demonstrate the inability for these subsidiaries to regularly participate in key strategic meetings or seldom experience visitation from headquarters in comparison to their highly desirable counterparts:

"(HQ) genuinely were not interesting in sending anyone to the Wellington office as it's not relevant to the overall business so... (HQ) are going to send them to Sydney” - Interviewee H17

"Nothing like China, it [S2] had to beat the drum a lot harder to get attention..." - Interviewee F12

\subsection{HQ Attention Disparity and Expatriate Knowledge Sharing}

Through the interviews emerge two different themes related to HQ attention and knowledge sharing. Firstly, in the way of high-attention subsidiaries, some expatriates believed that HQ attention levels reflect the weight of these subsidiaries; implying a strong expectation to exert greater knowledge sharing efforts in order to further develop the subsidiary and meet the expectations of HQ. The findings mimic the core beliefs of the self-determination theory (SDT), which implies individual's behaviour, may be motivated externally (i.e., controlled motivation) and internally (i.e. autonomous motivation) (Cockrell \& Stone, 2010). The former prevails as more relevant to the findings as controlled motivation refers to the incentives based on which individuals demonstrate behaviours that explicitly contribute to their core-self needs and benefits. This includes reward systems, formal or informal evaluations from others, and status within significant groups. In the case of the expatriate, many of those interviewed felt that the natural role of their job aligned with the perception from HQ that they exist to diffuse knowledge across different MNC units in any given circumstance. Similarly, this analysis aligns with the characterisations of reasoned action theory (Ajzen, 1991). Similar to SDT, subjective norms; behaviour guided by the beliefs about the expectations of actors significant to the individual and the 
motivation he or she has to comply are also considered one of the more powerful determinants of human behaviour. Therefore, the motivations of these individuals with respect to HQ and the level of attention a subsidiary receives are a reflection of certain behaviours derived from the sense of pressure or necessity of performing these behaviours to achieve these desirable outcomes as was the case for interviewee G16 and F15:

"I think the perceived value has a huge amount of impact on the willingness to share knowledge..." - Interviewee G16

“... [HQ attention] will have an overall impact on my mental positioning of these subsidiaries and what I can do as a person to achieve these expectations...” - Interviewee F15

Conversely, the findings also suggest a variance in expatriate knowledge sharing between cases of similar attention receiving subsidiaries versus subsidiaries demonstrating an evident difference in level of headquarter attention. This particular finding supports that an evident discrepancy in HQ attention may in fact lead to more valuable knowledge sharing than subsidiaries with similar exposure to HQ. Consistent with recent conceptualisations of the attention based view of the firm, similar subsidiaries do not create any beneficial synergies as these units will often have comparable kinds of knowledge, connections, and concepts. Research implies in such cases, there is an increased competitive nature between the two subsidiaries to get HQ attention, whereas our findings allude to the idea that marked differences in HQ attention, specifically when moving from high attention to low attention subsidiaries, will promote active knowledge seeking behaviour. The link between the perceived vale of knowledge and knowledge sharing in relation to the findings suggest that the expatriates' believe it to be beneficial to draw on these efforts, strategic value and HQ connections and share the knowledge accumulated in future assignments which majority of interviewees support:

"The higher the strategic value of that subsidiary to the business the more knowledge you will have to share... There is a lot of information that needs to be shared from [S1] into [S2]" - Interviewee F6 
“...there were certainly markets ... had more involvement with $H Q$ and certainly the expatriates that worked across these subsidiaries certainly communicated to close these gaps." - Interviewee F15

More central to the concept of HQAD, the foundation of the current research, explores how the data addresses the focal research question: to explore the relationship between HQAD across subsidiaries and expatriate knowledge sharing. The findings emphasize, although the perceived value of knowledge is highlighted as a mechanism by which expatriates can be able or motivated to share knowledge, it can be split into two perspectives; each of which suggest to contribute to the confidence an expatriate has in their abilities to share as a stock of knowledge. It transpires that HQ attention as a capability enhancer inherently draws on the sender-receiver model. The findings highlighting the most critical assumption of the model, which is that, a combination of characteristics between both units influences the knowledge sharing process. The findings emphasise the acquired knowledge from the previous subsidiary should be analysed through the lens of the sender (i.e. the expatriate) but in this, also identify how the perception of knowledge from the receiver (i.e. the current/subsequent subsidiary colleagues) effect the KS process. Henceforth, we divide the following findings into two sections: Expatriate perceptions of acquired knowledge from the previous posting [S1] and subsequent subsidiary [S2] perceptions of the same knowledge.

\subsection{Expatriate Perception of Knowledge Acquired from Previous Subsidiary}

The findings support key assumptions of the sender-receiver model and abilitymotivation framework with specific regard to the knowledge value of the expatriate moving between subsidiaries. Among other traits, expatriates, as knowledge senders are shown to be in a position to better articulate and communicate developed knowledge when they have been exposed to environments that demanded a lot of interaction with corporate $\mathrm{HQ}$. As the findings highlight, these forms of knowledge can be acquired and strengthened through training, education, observation and involvement. More specifically related to observation and involvement, it the data 
finds that stronger observations for insight and new knowledge are prevalent in situations where the expatriate has been exposed to higher levels of attention engagement from headquarters from previous postings. We characterised the expatriate as indulgent in 'expert work', which are reflected in the findings as it transpires expatriates are able to enhance their own skills and knowledge base through extraction of best solutions from different locations which are often aided with the guidance of HQ and their involvement at the time. As such, the expatriate exposed to these relations increases their individual understanding of the international operations with a better alignment with the HQ vision, thus in a better position to benefit other subsidiaries. Particularly in the transition of high-attention to low attention subsidiaries, the findings suggest expatriates generate desirable information/connections that would deem them as an advantageous knowledge stock for other subsidiaries to learn from. Additionally, the observations support that highattention subsidiaries are involved with HQ in key strategic or operational decisionmaking, which are often visibly shared by HQ. Many of the respondents are in support of this assumption and relate the high levels of attention as a means by which the respective subsidiary possess unique resources and connections that would be beneficial to share in the future.

"[S2] benefits from the fact that I had HQ and [S1] experience... With the transfer of knowledge yeah hugely so a large amount of what I do here is replicated the good things..." - Interviewee $\mathbf{F 9}$

As highlighted by Poss and Pedersen (2002) stronger knowledge/capabilities could include: investments in internal knowledge production, direct linkages to local players, and knowledge based in more diffuse linkages to sources of information in the environment. It is assumed many low-attention subsidiaries are either not exposed to this type of useful knowledge at the same level or able to generate on their own without the support and resources from HQ. Our data analysis suggests that the majority of expatriates exposed to high attention receiving subsidiaries prior to their subsequent/current assignment consider HQ attention as adding a novel competitive edge to the existing knowledge stock of the subsidiary; observing provision of extra resources, investments and opportunities to be involved in key strategic decision making which from the expatriates' perspective, adds to the knowledge stock of the 
individual who are then able to carry this know-how, know-what knowledge to other projects. Some respondents felt that HQ attention was especially evident for largescale MNC operations that included the high-attention subsidiary such as joint ventures and acquisitions which require corporate intervention, thus adding to the superior strategic intelligence overall of the firm and employees in that subsidiary. Therefore, expatriates who inherently develop their own competency levels simply by being exposed to this subsidiary environment are stocks containing highly valuable knowledge, which can be beneficial to other MNC units:

“... you could easily learn from some of the more successful subsidiaries that headquarters were involved with, what they were doing and take it back to your own country and people...."- Interviewee F15

\subsubsection{Confidence in knowledge}

The findings emphasise the role of confidence an expatriate has in their acquired knowledge from their prior assignment in knowledge sharing. More specifically, the findings suggest, that there are different outcome expectations, which can occur, both of which add to the confidence felt by the expatriate. Firstly, performance-related expectations are associated with improvements in the subsequent subsidiaries performance associated with the knowledge from the prior subsidiary. Contrastingly, personal expectations relate to changes in status, rewards or praise. The findings of the study reflect current empirical support suggestion that individuals' benefits (e.g., reward, enjoyment in helping others) may act as motivators of knowledge sharing (Bock and Kim, 2002). Under the assumption of a high to low-HQ attention transition, the findings reveal that an expatriates' positive perception of knowledge acquired builds confidence in their own capability to perform as a resourceful asset. A significant proportion of those interviewed felt that in being exposed to heightened HQ attention to processes, investments and resources, the expatriate the knowledge they learn in this subsidiary as reliable and valuable. The data implies that this perception of 'superior' subsidiary competencies enhance the expatriates' confidence in their knowledge competencies as an individual. Evidently, we interpret such findings to imply that the thought of sharing trustworthy knowledge to future 
subsidiaries easier when the expatriate believes in the value of the knowledge they have to offer. In having direct communications and links to development of strategy or other useful resources from headquarters, the findings suggest the more likely the expatriate is to perceive their own accumulated knowledge from this environment as competent or superior and worthy of being shared to other MNC units. Thus adding to the overall level of confidence the expatriate exhibits in his own ability to share accurate but more so unique and beneficial knowledge, which they are confident, will be recognised by other units:

“...it had proven success in an important market like New Zealand [S1], which did carry weight in the overall scheme of things" - Interviewee E5

"We learnt so much more in the [S1] larger subsidiary about good customer management and financial management and we brought all that information and was able to turn NZ around using the success of Australia at the time" Interviewee $I 18$

Suggestively, the confidence felt by expatriates' in their knowledge naturally influence subsequent behaviours, this being the action of sharing knowledge in S2. Based on the above, the findings depict expatriate transitions from high-low attention subsidiaries reported they were more likely to exhibit internal motivation and committed behaviour toward sharing knowledge acquired across to their subsequent/current subsidiary as they felt the learning experiences of their first assignment are worth passing on to value add to a low-attention subsidiary. In conclusion, the findings assert HQAD in these transitions are beneficial toward building expatriate confidence and motivation to share in S2. In many of the cases, the expatriate was aware of the disparities and this often facilitated a sense of obligation to the new subsidiary, as it was obvious to the expatriate that $\mathrm{S} 2$ was not in a position to have access to the same kinds of resources or corporate involvement as their previous posting. An important issue emerging from these findings is the vitality of having an expatriate in these subsidiaries as without them, the lack of HQ attention evidently hinders the ability for low-attention subsidiaries to gain strategic knowledge relating to goals of the MNC in general. Provision of strategic knowledge proves beneficial for low-attention subsidiaries as it addresses the necessary contextual 
knowledge about actions that will also effectively attract headquarters' attention in the future (Dutton et al., 2001).

... I bought a whole lot of new aggressive skills (from S1) that could be applied to S2. . A lot of the knowledge ... made a difference. Technical knowledge and accounts knowledge that was from the more sophisticated and $H Q$ exposed subsidiary of $S 1$ were able to apply better to NZ because they never actually had it before. As an expat this was the only way for this knowledge to actually be shared so I was incredibly determined to develop the team... - Interviewee $\mathbf{I 1 8}$

\subsection{Subsequent subsidiary perceived value of knowledge from Previous Subsidiary}

Consistent with existing sender-receiver relationship theories, the findings attribute expatriate perception of relative knowledge using a second lens i.e. the characteristics and behaviour of the knowledge recipient unit. Evidently exploring how the outcomes of the resulting organisational behaviour relate to the same internal ability-motivation of expatriates. MNC resources that generate superior value are usually those developed within it (Argote \& Ingram, 2000). Therefore, per the knowledge-based view, internal subsidiary created and shared knowledge are the primary source of value creation for the MNC (Argote \& Ingram, 2000). Headquarter attention as the literature asserts is arguably one of the most strategically important and desired resources. The findings emphasise that attention from HQ adds to the knowledge base of a particular subsidiary. Consequently, this has an effect on internal behaviours of the expatriate in assessing how confident they are of their abilities as knowledge carriers.

The findings stress the absorptive capacity of the receiving subsidiary in relation to HQAD and knowledge. Low-attention subsidiaries for example may require novel information, thus these subsidiaries are shown to be aware of the potential to upgrade their knowledge stocks through knowledge received from either their parents or more successful subsidiaries that have close connections with HQ. Many interviewees 
observe S2 as showing the ability to recognise the value of the external knowledge brought by the expatriate and apply it to subsidiary operations when it came from a better place (Cohen and Levinthal, 1990). Evidently, drawing on the experience of the expatriate is considered advantageous to these units as internal knowledge is often tacit and can only be shared through extensive interactions with the local subsidiary employees. The study interprets this as recipient awareness whereby S2, similar to the expatriate, acknowledge HQ attention as aiding the development of core strategic competencies as a long-term strategy to value to the firm. Many interviewees support this with claims suggesting that low-attention subsidiaries are aware of HQAD but acknowledge the value of the unique skillsets and resources high-attention subsidiaries possess, as summarised by Interviewee F13:

“... [S2] probably saw them [S1] as a very strong value driver. Probably felt that [S1] got more resources and was really easy to get resources compare to themselves in [S2] but I think they understood why... I think everyone understands the relative importance of the two markets."- Interviewee F13

\subsubsection{Competence based trust}

The subsequent subsidiary, when aware of the benefits the expatriate possesses from S1, will treat the expatriate as an important member of the local work community with connections to higher authority and a knowledge stock of relevant information. Thus the findings establish the relevance of competence-based trust. There is a natural inclination for ones competency based trust in another to increase given the awareness of stronger knowledge. In the example of subsidiary colleagues, their perception and level of trust in the expatriate's competences is a reflection of their perception of the knowledge of the subsidiary the expatriate performed in prior; applicable to both transitions. The findings show that knowledge from the prior posting will be perceived as trustworthy if sufficient rational grounds exist for competence, such as evidence of prior experiences where expectations have been fulfilled (Inkpen \& Tsang, 2005). Interviewee D4 and I18 for example align in their observations depicting the subsequent subsidiary colleagues as aware and accepting of the unique resources expatriates can provide having come from subsidiary receiving high levels 
of attention from HQ. From this analysis, the findings imply that the awareness S2 has on the positive outcomes of strong HQ attention is closely linked to competence based trust. As such, the trust, colleagues in the new subsidiary have in the new knowledge transfers to the expatriate as the physical sender of this knowledge, as supported below:

"So because I was able to build good relationships with management [S1] and keep them that was a big tick for them [S2]. [S1] is a very big market and I was successfully able to work with the Japanese so [S2] are sure that there must be something in me." - Interviewee D4

"...if you know that another country that an expat is coming from has had good results and is also in the good books with $H Q$ then yeah knowledge sharing flows are a lot more easier to engage in and utilise. They have greater informational access to resources" - Interviewee $\mathbf{I 1 8}$

Conversely, some interviewees make observations on transitions from a low-attention to high-attention subsidiary. As expected, the interview findings present evidence to support the inverse effect to that of above. High-attention subsidiaries as perceived by the responding expatriates, often believe their operating size and contribution to the MNC as highly valued thus reflected by the experienced level of headquarter attention. What we interpret from the findings is that is high-attention subsidiaries are susceptible to a mentality to feel they are executing HQ strategy and objectives better, relative to others. Thus, the findings assert that such subsidiaries have a predisposition to disregard knowledge from elsewhere that does not possess the same if not more knowledge. In turn, the inclination to be receptive toward knowledge that do not possess high levels of competence based trust or is beneficial to the subsidiary is reduced as claimed below:

"Unfortunately because of ego and market complexities, sometimes there are situations where particular markets think they are the best and it is hard to teach them anything new... the majority were like... why do we need any help. "-Interviewee D4 
"I think you also have this ego at play and they think they are so big and we are the best and we can do it... London was more advanced than Melbourne so it wasn't like London was trying to get information from Melbourne." -

\section{Interviewee G16}

"I think there is some kind of flow on effect where big subsidiaries like [S2] let the size of their office get to their head and evidently it flows into the people's mindsets too... in my second move it was so much more different because now we are switched to the mindset of an Australian ...they want nothing to do with NZ knowledge..." - Interviewee $I 18$

\subsubsection{Expatriate perception of current subsidiary receptivity}

The data finds a linkage between high levels of competent trust toward expatriate knowledge and receptive subsidiary behaviour. Similar to the perception of acquired knowledge, the findings highlight HQ attention when linked to new and valuable knowledge or lack of can shape subsidiary receptivity and therefore work environments to either positively receive or reject new knowledge shared by the expatriate. We analyse the 'receptivity' of host subsidiary colleagues as presented by the level to which the collective subsidiary exerts not only a level of openness or cooperation but may also exhibit willing knowledge seeking behaviour. The findings imply the receptivity to be attributed to the value of the knowledge possessed by the expatriate, which is contingent on level of HQ attention the subsequent subsidiary receives relative to the prior. The findings show awareness and more importantly acknowledgement of value in knowledge from the prior subsidiary given HQ attention was higher. Interviewees thus believed the nature of low-attention subsidiaries as inclined to be more willing and open to accept knowledge from prioritised subsidiaries through expatriates in order to develop. The findings conclude that if a subsidiary's knowledge stock is incredibly low as is the level of HQ attention, it has very little to gain from exhibiting uncooperative behaviours with an expatriate coming from a more competent subsidiary. Hence, it is likely to be very willing to receive knowledge from external sources, thus making the knowledge sharing process easier for expatriates to engage in the sharing process: 
“... if you are a smaller ranked subsidiary and you need the help you tend to be more open and willing to listen to new knowledge from expats, from $\mathrm{HQ}$ from anyone..." - Interviewee $I 18$

“...[S2] is quite keen to get recognised and whatever so I think in terms of you know smaller locations being willing to absorb and take the knowledge from stronger locations... I think people here [S2] are very receptive to take on ideas ..."-Interviewee G16

HQAD (under the assumption of high to low-attention transitions) develop interest from subsidiary colleagues. The findings show colleagues to be more inclined to listen to expatriate experience and knowledge as it may increase their own knowledge base and connections. Similarly, the findings also suggest the expatriate to be exposed to social feedback exchanges within the subsidiary environment where they may learn the extent to which people perceive the value the previous subsidiary through general comments or conversation. Assuming positive outcomes, this adds to the overall confidence the expatriates place in their acquired knowledge. Thus, interviewees perceive receptivity when evidence of knowledge seeking behaviour toward the expatriate is exerted to build on the current subsidiary's knowledge stock. The findings show expatriate perception of receptivity will further increase the likeliness of sharing knowledge from their previous assignment as there is new confidence the information will be received well by recipients:

“...given the positivity and willingness of the [S2] subsidiary colleagues to take the information on board because they saw how beneficial it was, that evidently did make me feel a lot better about sharing the information... They were actively trying to make themselves better, which made me feel better about my whole entire process of sharing knowledge”-Interviewee F13

In contrast, the findings present an interesting outlook on the possible negative perceptions of subsidiaries with high HQ attention. The exceptions to the general trend of the findings underline how perceived fairness of allocation of headquarter attention, particularly when seen as unfair, in some cases weakens S2 reception 
following a high-attention to low-attention transition. The findings depict situations where the expatriate observed the subsequent subsidiary perceiving attention disparity in terms of neglecting "strong financially contributing" subsidiaries in favour of "less sophisticated" subsidiaries. With such comparisons, the findings highlight inverse outcomes of receptivity for high HQ attention. Exemplified in the case of Interviewee F11, his previous subsidiary although a strong contributor to the $\mathrm{MNC}$, did not receive much attention relative to his subsequent assignment. More interestingly was the perception of how knowledge sharing would be effected if his assignments were reversed:

I think there is a perception in [new S2] that areas like [new S1] get an undeserved ranking or profile attention... So there was probably a feeling of hey we [new S2] are over here out in isolation... flowing from that... [S2] may not be as receptive to hearing knowledge because they think that everything that comes out of those markets is overemphasized anyway...I think I would have done it (share knowledge) less frequently”-Interviewee F11

Interviewee F11 considers the possibility there are low-attention subsidiaries that are critical of their prioritised counterparts. The implications of this particular opinion are two fold; firstly in that the conceptualised competence-trust colleagues have in the expatriate are scrutinised as information generated in 'underserving' markets are "overemphasised" and carry no real weight from the view of the subsequent subsidiary and secondly, it dramatically reduces receptivity in accepting outside knowledge which make it difficult for expatriates to willingly engage in knowledge sharing when they perceive colleague reactions as sceptic. This particular finding suggests the irrelevance of whether the knowledge from the prior assignment is enhanced from the as receptivity to the knowledge may go amiss due to the perceived unfairness of headquarters allocation of attention. Similarly, Interviewee A1 also made remarks that alluded to the idea that despite strong levels of HQ attention received by her prior post, animosity remained among new colleagues, which was shown to impair her sharing of knowledge. She was of the opinion that due to the weak receptivity, she made avid attempts to tailor not only the type of knowledge, but also the level of knowledge shared: 
"I worked out quite quickly that not everyone [S2] was as enthusiastic about [S1] as I was so I needed to dose my sharing and be very mindful of who was interested and who wasn't interested... I think I did (share knowledge from [S1] less often" - Interviewee A1

Interviewee I18 contributes his thoughts to this theme but reflects on the intersubsidiary relationship and the attitudes within that may weaken expatriate knowledge sharing. Based on his experience, he acknowledged negative inter-subsidiary relationships derived in a social context have the potential to influence the intentions of expatriates trying to engage in knowledge sharing. Interviewee 17 also acknowledges his first assignment to be positioned as receiving high-HQ attention however stated the enhanced knowledge shaped this subsidiary to act antagonistically "toward smaller subsidiaries". He observed these actions to form negative perceptions in the subsequent subsidiary. Additionally, he observed negative reception to the extent where he comments that if his following subsidiary had been a strong financial performer or if he was of the same nationality as his previous subsidiary, the receptivity of his second subsidiary toward learning would have been dramatically reduced due to the attitudes within the subsidiary. It is concluded that although the key findings suggest knowledge sharing to be more likely in high to low transitions, this may not always the case if subsidiary attitudes are strong enough to weaken the relationship:

"If I had been [S1] nationality, things would have gone a lot differently... I do not think I would have been able to share anything at all...If [S2] had been performing well and just fizzing, ...from a knowledge sharing perspective, I think there would have been a lot more unreceptivity to new ideas."Interviewee 118

\subsection{Contingency of the relationship between HQ Attention and Knowledge Sharing}

The finding emphasise the importance of understanding the key role of positive relationship qualities (social trust and shared vision) between two subsidiaries. Given 
the effect of HQAD on the knowledge base of the subsidiary, it is implied there need be a strong understanding of other social factors which relationships may depend on for knowledge sharing. Majority of responding expatriates agreed their knowledge sharing efforts were derived more in social contexts, therefore confirming that knowledge in the context of this thesis is also socially constructed. The findings further highlight functions of socialisation; job/function relevancy and attitude when linking headquarter attention disparities to expatriate knowledge sharing. As knowledge sharing is not a direct process, the influence of other variables is inevitable therefore the findings also draw on the relationship between expatriate and host country colleagues.

\subsubsection{Socialisation}

The findings emphasise the contextual environment by which expatriates are emerged into shape their perception as to whether knowledge sharing is easy to engage in. It is made apparent in the findings that positive observations of subsidiary socialisation culture helps the expatriate to believe that knowledge sharing in the new environment is easy. The findings therefore confirms the role of subsidiary social interaction between expatriates and host subsidiary colleagues, with specific regard to the earlier stages when initial social bonds can be formed (Noorderhaven and Harzing, 2009). As such, intensive socialisation is more likely to develop social trust where expatriate and host subsidiary colleague can understand one another, thus proving more beneficial toward the process of knowledge sharing. This is assuming the existence of a proactive culture where both parties are actively and willingly communicating with one another. We interpret the findings to suggest that the subsidiary community where individuals alongside the expatriate reside, is where which socialisation becomes applicable:

“... you can walk into the office here [S2] and know everyone and there is a nice friendly culture here whereas you walk in [S1] and you don't recognise anyone and don't bother to say hi..." - Interviewee G16

Although the main findings present perceived value of knowledge as the key mechanism to share knowledge, the data also suggests the strength of this relationship 
can be moderated given the intensity and frequency of the socialisation between expatriate and host subsidiary colleagues. Majority of those interviewed acknowledge the key advantages to frequent social interaction with colleagues as being: knowledge sharing, cultural intelligence and feedback Repeat encounters help promote awareness of co-worker competencies and fostering office relationships, which a large portion of our interviewees considered an integral part on their knowledge sharing behaviour (Hua, 2010). Not all social relationships are homogeneous; more rather some types of interactions may be richer than others for knowledge sharing purposes. This extends to whether the expatriate perceives social exchanges to occur more in given environments such as closer office arrangements, frequent and consistent meetings and/or outside the workplace socialising. For example, the findings emphasise the cognitive benefits of close-knit workspaces that facilitate interactive socialising among colleagues; promoting the natural flow of knowledge. More so, the findings justify the belief that physical space has a key role in the formation of social interactions, arguing that relationships not only between host subsidiary colleagues but host colleagues to expatriates are likely to develop on the basis of contacts made within the same shared space. Alternative streams of the knowledge management literature accentuate the importance of office space designed to facilitate socialisation, fostering frequent collisions between people and developing meaningful interactions that increase learning behaviour over time and convey optimism to all engaged in the process. Based on the findings we propose that the trust required for positive receptivity is not able to form instantly using only the proposed mechanism of stronger knowledge. Rather, social trust is gradually built through communication by individuals who are able to interact with each other on a daily basis in the office space as supported by the following:

"I think part of it [knowledge sharing] is the way that the office was set up so I think that there was more opportunity for people to speak and have conversations with each other in the [S2] subsidiary just with in the office setup so that made everyone more open" - Interviewee F7

This is theoretically consistent, as the findings assume positive receptivity would imply active knowledge seeking behaviour from S2 colleagues in the form of initiating social conversations regularly. The current research addresses that 
expatriates positioned in complex environments where engagement is minimal; the perception is that they will encounter greater challenges in adjusting to the social environment, which evidently flow on to other behaviours as highlighted below:

"[S1] are not necessarily talking to people that they have met before or outside of Chicago... so there is an element there, which keeps everything closed..." - F11

\subsubsection{Functional/Job relevance}

The research integrates benevolence and competence based trust as an integral aspect of expatriate knowledge sharing. Both forms of trust are able to exist autonomously in the context of the expatriate- subsidiary colleague relationship. For example, an employee from the expatriate's second assignment can trust that the expatriate knows the information the subsidiary requires (competence), but they may not trust that the expat will be willing to share the knowledge when it is needed (benevolence). Contrariwise, the employees may be confident that the expatriate is willing to assist the subsidiary with their knowledge (benevolence), but the expatriate may not possess the knowledge or skills required (competence) as they were situated in an irrelevant market or different functional role to the one at hand. This translates to the findings where interviewees commented that the relevancy of their developed expertise from the subsidiary prior in conjunction with the perception of a high-attention subsidiary gave way to a more receptive environment and relationship with colleagues in their current/second subsidiary. However, some interviewees also said that due to the change in their functional role which may have seen them change positions or departments, the actual level of knowledge related to the current business was considered not useful or relevant.

Drawing on the social capital literature, the findings support the assertion that shared vision i.e. the extent to which different individuals share the same visions and goals, is a critical cognitive aspect that characterises social relations which in turn influence knowledge transfer (Inkpen \& Tsang, 2005). This is particularly relevant for when the subsidiaries share a comparable foundation for knowledge due to similarities in functional role (Chow and Chan, 2008; Cummings and Teng, 2003). Shared vision, often related to the concept of shared job role and/or function enables the MNC unit 
to assimilate a common understanding of the positive and negative outcomes of the knowledge shared by the expatriate and makes application easier. Similarly, perceived value and benefits of the knowledge from the previous subsidiary are shown to positively affect both expatriate and subsidiary perceptions.

However, the findings depict this relationship to be further strengthened or weakened by the alignment of job functions across expatriate assignments. The findings confirm the need for competence-based trust i.e. the extent to which host subsidiary colleagues trust the competences and credentials of the knowledge sender. In the case of expatriates who have moved from high-HQ attention subsidiaries, the findings show that they exhibit reliability in performing complex roles in strategically important markets alongside possessing excellent qualifications and special connections to resources. However, what is considered most crucial to knowledge sharing the relevancy of successful experience in the same or common functional role. High levels of competence-based trust allows the evaluating subsidiary colleagues to trust the expatriate more than simply admitting they have better knowledge. This is shown to increase the intensity of initiating knowledge seeking behaviour from those the subsidiary trust to be competent in the relevant field. To acknowledge this proposition fully, we note the contrasting outcomes of irrelevant knowledge as noted by Interviewee H17:

"...everyone else in the office was focused on a different area completely which is like sales marketing ... It was quite a different focus but also very small...They didn't having anything to do with support or you know technical things, they were sales and marketing so me being a geek trying to talk to them about all the processes and systems they do not care at all." Interviewee $\mathrm{H} 17$

In support, few respondents extend their remarks on functional relevance to outline implications at the corporate level for successful knowledge sharing. Many of the expatriates felt that corporate HQ placed heavy emphasis on the training and development of local staff. Consequently, the role of functional relevance seems to play a large role in this process, as the key aim was to train local individuals up to be able to perform the expatriate's tasks when they leave. This inherently suggests 
expatriates are required to have a strong level of relevant competence to be able to pass on relevant skills and knowledge to future local managers for the same role. Learning is more achievable when drawing on the existing causal maps constructed by the existing functional roles within the subsidiary. The convergence of functions and expertise are vital to the subsidiaries ability to understand and assimilate knowledge from external sources. Interviewee E5 comments explicitly that the first step in training local managers required $\mathrm{HQ}$ and the expatriate to agree on who to train on the basis of commonalities as stated below:

"[knowledge sharing] we did with our subsidiary staff training but with selective people where we checked where there function was related and having a common knowledge sharing experience”-Interviewee E5

Hence, the findings largely support the importance of job/functional relevance. Majority of interviewees felt the knowledge sharing process more likely between similar departments or functional units. The findings in this theme presents similar rationale to previous antecedents of barriers to expatriate knowledge sharing in that as is the nature of an $\mathrm{MNC}$, one cannot assume all subsidiaries of the MNC are identical nor can one assume constant consistency across expatriate assignments. If the functional relevance gap between subsidiaries is too great, learning may become incredibly difficult. As evident through Interviewee 15, the awareness that ones specific knowledge stock is not relevant to the new environment create inhibition in wanting to share information related to that specific content. Consequently, the responses of our expatriates seem to strengthen the well-known argument that expatriates and/or repatriates are placed in irrelevant positions to that of their previous roles and thus perceive their accumulated knowledge as non-relevant to their current assignment as described:

"[S2] is not in the same business function... we are not having anything to do with one another ... when I switched, I also switched units so we don't have any SAP work here in [S2] so there wasn't anything relevant."- Interviewee G16

“...why would I want to share my knowledge to in an irrelevant part of the business...yes if they had a tech support centre over here [S2] then yes I 
would say that would want to share my knowledge."- Interviewee H17

“...[When] you move countries but don't move businesses [function] there is a far greater opportunity for knowledge sharing and opportunities for success than an instance where you change both organisations (function) and geographies at the same time. I would change one at a time rather than both at once because if you change both at once it [KS] is very difficult". Interviewee A1

As emphasised above, Interviewee A1's perception on functional role surrounds the centrality of creating synergies between MNC units. Commonalities provide the necessary means to facilitate increased in-house conversations and expatriates would be more likely to experience host subsidiary colleagues taking initiative in seeking the individual out for knowledge sharing purposes. Henceforth the role of functional and/or job relevance can extend to the behaviour of expatriate knowledge sharing in that the level of social trust accompanied with competence trust and shared vision can influence expatriate motivations. Needless to say, the similar functional roles overall promotes mutual understanding of knowledge relevance and therefore strengthen the crucial bonding mechanism could help S2 colleagues learn and integrate knowledge shared by the expatriate. 


\section{CHAPTER FIVE: DISCUSSION}

This thesis develops a framework explaining the role HQ attention disparity (HQAD) plays on expatriate knowledge sharing. Consistent with the ABV and research linking the ability-motivation framework to the sender-receiver model, the study presents a dual perceptual orientation related to expatriate knowledge acquired from their prior assignment. Two crucial factors drive the dynamics by which HQAD can effect expatriate knowledge sharing. First is the characterisation of the expatriate and their perceived confidence in the acquired knowledge from the assignment prior. The extent to which expatriates anticipate the knowledge will benefit the recipient subsidiary provides a frame of reference for the second factor, the perceived value of knowledge from the subsequent subsidiary perspective.

The perception of knowledge creates specific interactions when applied practically. Expatriate confidence in acquired knowledge from a higher HQ-attention receiving subsidiary in conjunction with the aligned opinions of the subsequent subsidiary characterises the nature of occurring interactions. Should colleagues perceive the value of knowledge possessed by the expatriate from the previous subsidiary as weak, this is shown to contribute toward unwillingness in learning from the expatriate. These strained interactions are argued to weaken knowledge sharing activities. More prevalent in the findings, where expatriate and subsidiary perceptions align, learningoriented behaviour is depicted as positive, as the new knowledge is perceived stronger and valuable to the knowledge base of the current subsidiary. Accordingly, higher engagement is required to exploit the knowledge sharing process therefore facilitating positive expatriate-colleague interaction, which enables KS.

The presented evidence of HQAD is not novel it remains critical to the current research. The findings correspond with ABV literature, as attention is relative and not always distributed equally. Reporting these findings were important as they are a necessary condition in order to compare the value of knowledge between higher-HQ attention subsidiaries to low HQ-attention subsidiaries, allowing for the current study to take place. Based on the research findings, the resultant framework has been derived to help better understand the process of relating HQ attention to that of expatriate knowledge sharing. 


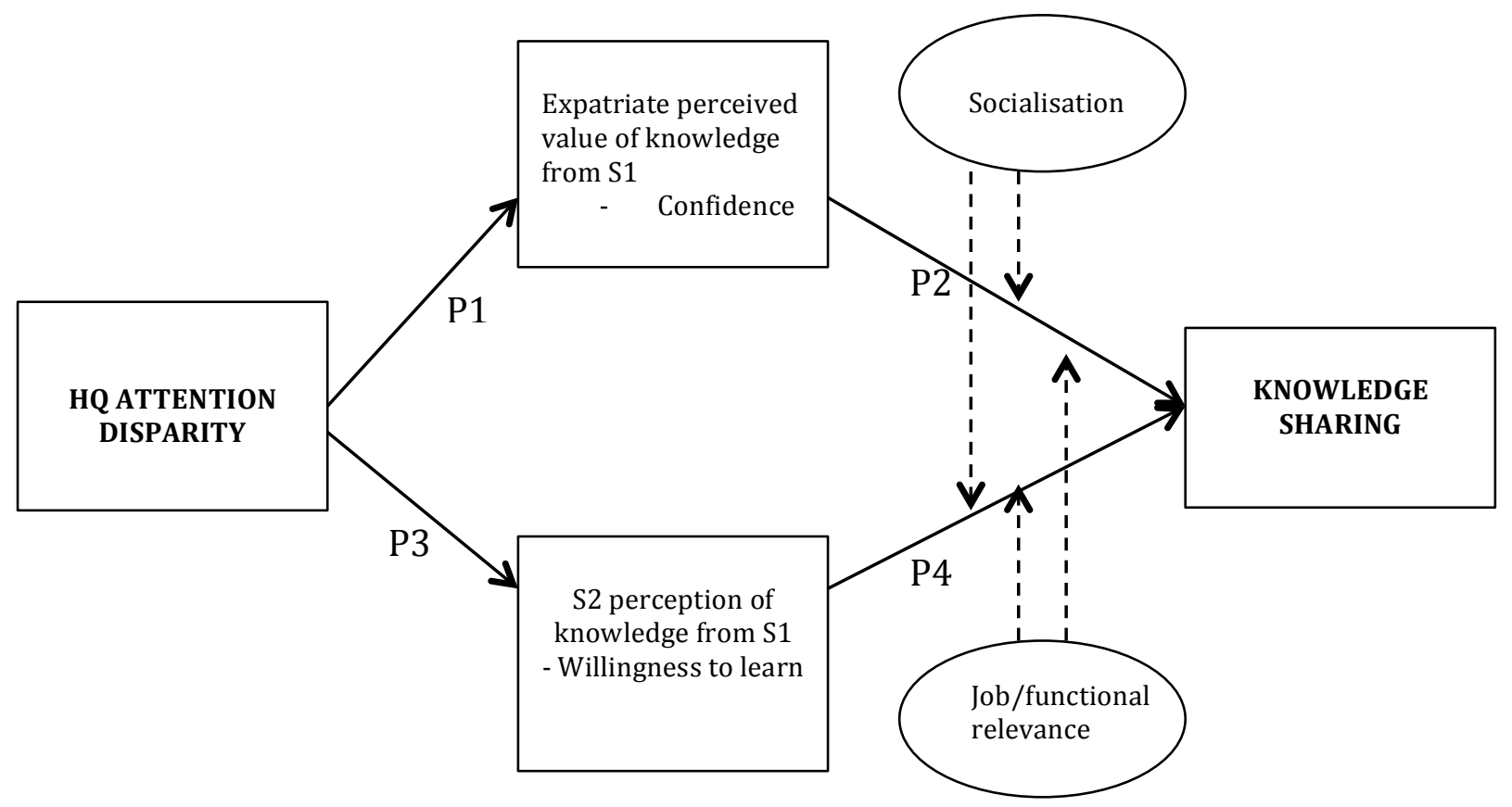

\subsection{Effect of HQ Attention on Expatriate Knowledge}

Headquarter attention encompasses the various HQ interactions when interacting with a subsidiary, including but not limited to; resources, conferencing, telephone calls, emails, report mentions and visitation. These reflect Bouquet and Birkinshaw (2009) who conceptualise positive attention across constructs of supportive, visible and relative aspects. Accordingly, higher levels of HQ attention add to the strategic intelligence of a specific subsidiary and expatriates within. The discussion draws on the term 'perceived value of knowledge' to reflect the organisation specific proficiencies that may be imbedded within the expatriate. The study finds expatriates assigned to subsidiaries receiving high levels of HQ attention naturally strengthen their own knowledge proficiencies through exposure. Presumably, this is knowledge which subsidiaries receiving lower levels of HQ attention are not exposed to or able to generate on their own, emphasising a gap in intelligence (Ocasio, 2011). Supported in the literature, the expatriate's confidence emphasises both self-efficacy developed by Bandura (1997) and perceived value of knowledge (PVK), defined as the worth an individual assigns to his or her own knowledge (Ford and Staples, 2006; Castañeda and Ignacio, 2015). Likewise, in the context of S2, competence-based trust describes the extent to which individuals believe another individual is knowledgeable. The findings observed in this study mirror those of the previous studies that have 
examined the effect of competence-based trust thus we are able to propose that given the expatriate has moved from a high-attention receiving subsidiary, positive selfperceptions of the knowledge acquired from S1 will elicit feelings of confidence in the knowledge from this origin. These perceptions are found to be the key element linking HQAD to knowledge sharing.

Proposition 1: Expatriates moving from a subsidiary with higher levels of $H Q$ attention to a lower one tend to have stronger confidence in own knowledge

\subsection{Effect of Expatriate Perceived Value of Knowledge on KS}

The Theory of Reasoned Action (TRA) implies an expatriate may have intention to share valued knowledge, however they can still lack knowledge sharing behaviour due to a combination of external influences. Comparable research alludes to several reasons individuals prefer not to share valuable knowledge, which the current research took into consideration as it aligns with other knowledge sharing theories, such as social exchange theory (SET) (Razak et al., 2016). Expatriate KS, particularly after moving from a higher HQ-attention subsidiary, support SET in that it defines an exchange of a valuable resource, which is expected to benefit both parties. The rational behaviour of the expatriate under SET and similarly self-determination theory assesses the likelihood of rewards gained from the social exchange. This could have applied to our interviewees however the outcomes did not corroborate with findings suggesting expatriate knowledge sharing occurs when rewards exceeded costs (Razak et al., 2016). Instead, expatriates confident in their knowledge feel more autonomously motivated in selecting their KS behaviour based on curiosity, care, or abiding values. More rather, the expatriate has a perception to fulfil the needs of the subsidiary by helping them develop with stronger knowledge created in S1 with higher attention from HQ. Similarly, PVK, conceptualised by Ford and Staples (2006), explains the perspective of the expatriate when assessing knowledge acquired from the previous subsidiary, with the intention of sharing in the next. The assumption is that contextual knowledge developed in a subsidiary receiving higher HQ attention is advantageous to share to other units. Ford and Staples (2006) argued that when the knowledge sharer does not lose value of this knowledge, the intent to 
share is far greater than if the knowledge is regarded as singular or unique. We diverge from this opinion, recognising expatriate knowledge from higher HQattention subsidiaries as 'unique' due to the input from HQ in creating the knowledge. It is not however regarded as 'singular' as the foundation of this knowledge is still applicable to other MNC units.

In context, the concept of self-efficacy describes the beliefs an expatriate has about their abilities to execute required actions, in order to produce expected results i.e. share knowledge effectively across assignments as per the expectations of HQ (Hsu et al., 2007). This is contingent on confidence the knowledge is worthy of sharing as supported by Bock and Kim (2002) who found judgment of contribution to subsidiary performance has positive effects on KS. Moreover, if expatriates believe they will be able to perform action with great skill, they may be more likely to expect positive outcomes than expatriates who doubt their knowledge and capabilities (Cabrera et al., 2006; Hsu et al., 2007). The study relates these theories to the way expatriates assess the needs of their current assignment, e.g. if they received lower HQ attention than the previous. This influences the way they act with respect to their KS behaviour (Bandura, 2000). Conclusively, the study was favourable of positive outcomes whereby the expatriate exerts higher levels of ability and motivation to share knowledge so their current subsidiary's intellectual capital could be leveraged. This is more prevalent if the expatriate perceived this subsidiary to receive less HQ attention relative to their previous posting. HQAD is shown to influence the expatriate to utilise confidence and try to readily assist across MNC units.

Proposition 2: The stronger confidence the expatriate has in their knowledge, the more motivated they are to share the knowledge with colleagues in the current subsidiary

\subsection{Subsequent Subsidiary's Perceived Value of Knowledge}

Drawing on the sender-receiver model, perceived value of knowledge cannot be assumed stronger only by the knowledge sender in order for successful KS. The study did not collect perceptions of the host subsidiary directly but rather interpreted through expatriate observations. As the key findings indicate an associated perception 
of the acquired knowledge through two important perspectives, expatriate interpretations of subsidiary perceptions are justified as an accurate representation. Using this lens, the research considers S2 colleagues perceived value of knowledge as another significant contributor. The research finds S2's current knowledge base can be distinguished as an important variable affecting the absorptive ability of the receiving unit (Cohen and Levinthal 1990). The absorptive capacity of the knowledge recipient has been widely acknowledged as an important enabler to interorganisational learning. Applied to the current research, the most relevant aspect of this theory is the subsidiaries ability to recognise the value of new, external information. HQAD enables subsidiary development of new insights through expatriate knowledge sharing, supporting strategic and competence development (von Krogh et al. 2001).

Not all HQ-subsidiary relationships are homogeneous; more rather some relationships create richer synergies and knowledge than others. As stated, subsidiaries receiving high levels of attention end up possessing advanced resources, connections and insights due to the strong relationship with HQ. Notably, the findings reflect awareness where low-attention subsidiary colleagues acknowledge the difference of HQ attention they receive compared to other subsidiaries. S2's ability to exploit knowledge is largely reliant on the subsidiary's ability to understand and accept the value of the knowledge brought by the expatriate in a positive way where it enhances the current knowledge base of the subsidiary. The study finds competence-based trust affects both expatriate and S2 colleague evaluations of knowledge but more so the latter. Competence trust is a quality-enabled skill that is shown to reduce uncertainty associated with cross-cultural interactions such as the expatriation process. Where perceptions regarding the value of knowledge align, it implies a high level of competence-based trust given from S2 colleagues to the expatriate. This argument has its roots related to person-perception research, which assert that individuals tend to weight positive information about knowledge heavily (Reeder, Hesson-McInnis, Krohse, \& Scialabba, 2001). 
Proposition 3: Subsidiary perceived value of expatriate knowledge increases if acquired from a subsidiary that received higher levels of headquarter attention

\subsection{Effect of Subsequent Subsidiary's Perceived Value of Knowledge on KS}

There are similarities in the current study to those described by Hansen (2002) who found direct relationships between MNC units were conducive for knowledge sharing. The current thesis aligns more so with established empirical evidence supporting the role of positive interpersonal relationships between international expatriates and local staff in the successful transfer of knowledge (Bonache \& Zárraga- Oberty, 2008).

Accordingly, the implications of the above discussion argue the linkage between HQAD and knowledge sharing of expatriates as a complicated process dependent on the knowledge characteristics, relationship context and learning abilities (Goh, 2002). Firstly, the research establishes that competence-based trust facilitates the knowledge sharing process through expatriate confidence. Trust can also however aid the knowledge sender and recipient helping each other learn and understand new external knowledge (Lane et al., 2001). More importantly, trust is shown to affect knowledge sharing by creating a number of necessary conditions such as openness and receptivity (Nahapiet \& Ghoshal, 1998).

The research accordingly presents subsidiary environment as a very important contextual factor for the expatriate to share acquired knowledge from high-HQ attention origins. Specifically, the receptivity of new colleagues is noted as the primary aspect. A basic pre-determinant of inter-organisational learning is the atmosphere within the relationship which the current study draws on with respect to perceived levels of subsidiary receptivity, otherwise defined as, openness to learning new knowledge. Subsidiary receptivity represents the beginning steps in the learning process and can be characterised by open and mutual intent to learn and transparency (Johnson and Sohi, 2003). Subsidiary receptivity therefore characterises S2 openness to learning, which can therefore be seen as the starting point to successful knowledge sharing (Morey 2001). However, the subsidiary learning environment is contingent on the learning efforts of the individuals within. Accordingly, these elements are seen to 
encompass the intent, possibility and ability to learn from the expatriate as an external source.

Henceforth, the knowledge sharing outcomes of the expatriate can also be characterised by positive learning-oriented behaviours demonstrated by the subsequent subsidiary. Knowledge characterised by high-HQ attention that are also perceived as value adding to the subsidiary increase willingness to learn. Hence, we anticipate new colleagues of the expatriate to become more receptive toward accepting knowledge from the expatriate's previous assignment. In a more practical sense, the previous proposition catalyses profile building behaviour from lowattention subsidiaries when colleagues recognise the perceived benefits to be gained from exploiting knowledge passed on by the expatriate. The willingness to learn can therefore be realised in a subsidiary that is prepared to question its current practices in search for more efficient ways of operating as presented in the findings (Child, 2001). This suggests low-attention subsidiaries demonstrate desire to gain new knowledge based on the acceptance that beneficial knowledge can originate outside the subsidiary. This further supports existing theorisations that expatriates are used in building reputable subsidiary profiles. Moreover, consistent with studies claiming low weight subsidiaries often take initiative lead approaches in attempts to attract HQ attention (Bouquet and Birkinshaw (2008) which the research suggests the outcome as drawing on the expatriate's knowledge.

In conclusion, the perceived value of knowledge, when positive, further motivates the expatriate share their acquired knowledge. However, perceived receptivity of host colleagues according to the study will thus be contingent on the expatriate's ability to reduce uncertainty, drawing on insightful and useful additions to the knowledge base of the current subsidiary. Based on this, the current research finds the subsequent subsidiary's perception of knowledge to be a foundation enabling positive receptivity from colleagues. As a result, expatriate confidence enhances as the individual associates further positive associations of their own abilities, increasing motivation to share knowledge. 
Proposition 4: Colleagues in the current subsidiary perceiving the expatriates' knowledge positively are more willing to obtain knowledge from the expatriate, thus more knowledge sharing activities take place

\subsection{Contingency of the Relationship between HQAD and Knowledge Sharing}

The structural dimension of social capital, combined with relational and cognitive dimensions are influential to knowledge sharing, as it is a human-to-human process (Naphiet and Ghoshal, 1998; Gupta and Govindarajan, 2000). Social capital in the context of the MNC is centrally focused on meaningful interactions encountered by expatriates as sources for social action (Audretsch \& Aldridge, 2012). The research suggests socialisation efforts and job/functional relevance to offer strengthening benefits in developing mutual understanding and enhanced trust to further facilitate expatriate knowledge sharing. Interaction alone is not considered sufficient to promote expatriate knowledge sharing behaviour however it does support collaborative efforts of subsidiary colleagues to interact with the expatriates with better knowledge. Accordingly, the combined influence of social interaction and job relevance is shown to have moderating effects on the key relationship. If shared functional/job processes motivate subsidiaries to share with one another, positive social relationships will enable them to do so more frequently and effectively, hence strengthening the relationship between expatriate and colleagues in the subsequent subsidiary.

\subsubsection{Effect of Socialisation on Motivation to Share Knowledge}

Transitions from high-HQ attention subsidiaries motivate expatriates are to share when there is confidence in knowledge. To a certain extent however, KS depends on the ease of communication in the contextual environment. Some studies suggest KS is better realised when newcomers i.e. expatriates exhibit proactive behaviours (Chiu, Hsu and Wang, 2006). This study found proactive communication exhibited by the subsequent subsidiary and a social context characterised by openness, learning, sharing and trust more likely to enable this process. The resulting firm culture can have crucial implications with respect to the way the expatriate perceives the way the subsidiary encourage learning (Child and Heavens 2001). For example, Cohen and 
Prusak (2001) emphasise the role of the physical workplace. Choices made about allocation of space both directly and indirectly shape the infrastructure of knowledge networks i.e. the rich social systems that assist individuals to learn faster and engage more deeply. Supportive of these findings the thesis highlight office proximity helped facilitate knowledge sharing as expatriates found it easier to "bounce off each others' ideas" (Dakir, 2012).

As such, the perceived learning environment can represent a key challenge with respect to how achievable the expatriate believes sharing to be within the given subsidiary. Subsequently, this perception may affect the willingness and motivation of the expatriate to invest time, energy and effort in sharing knowledge with their colleagues (Reagans \& McEvilly 2003). There is limited assumption that frequent social interaction on its own acts as an independent effect on intra-MNC knowledge flows therefore this thesis in light of the findings would rather propose that socialisation strengthens the effects of headquarter attention which are assumed to motivate expatriate knowledge sharing.

Proposition 5: When perceived efforts of socialisation in the subsequent subsidiary is positive, the expatriate is motivated to share knowledge they are confident in

\subsubsection{Effect of Socialisation on Subsidiary Receptivity}

The research considers socialisation to have a similar effect between the subsequent subsidiary's perceived value of knowledge and expatriate knowledge sharing, as receptivity to an extent bound by the structure of the firm. Subsidiaries with intent to learn will develop relationship structures that reflect these efforts. This highlights the preference for frequent and informal KS opportunities, as it is a more natural process. Spontaneous opportunities for KS, often found in informal social interactions provide a premise to build social bonds with fellow colleagues and build affect-based trust. In conjunction with the literature, the research supports affect-based trust as a necessary accompaniment to competence-based trust in the expatriate-S2 colleague relationship as it strengthens the overall evaluation of the expatriate to include trust at a personal level. Accordingly, the findings support frequent social interactions characterised by 
both affect and competence-based trust to indirectly increase the subsequent subsidiary's exposure to stronger knowledge from those with higher levels of HQ attention. The research therefore implies this reduces the likeliness of initial resistance or uncertainties that may occur under normal circumstances between the expatriate and colleagues.

Proposition 6: Socialisation positively strengthens the effect of host subsidiary perceived value of knowledge on expatriate knowledge sharing behaviour

\subsubsection{Effect Of Job/ Functional Relevance}

The research accentuate the contextual nature of knowledge sharing where it is associated to practices outside of which it has little relevance (Fox 2000; Plaskoff 2003). Potential for learning and sharing occurs where individuals are jointly engaged in a shared activity or community of practice (Fox 2000). Henceforth, an applicable concept is shared identity, which is a critical cognitive aspect that characterises the social relations (Inkpen \& Tsang, 2005) toward the subsidiary's absorptive capacity (Cohen and Levinthal, 1990). The MNC literature maintains that similarity in knowledge content among business units is a prerequisite for effective knowledge sharing. Accordingly, this basis can be derived from similar expertise in a previous job role or occupational background (Child and Rodrigues, 2003).

The findings therefore acknowledge that although it is encouraged expatriates share knowledge; the receiving subsidiary may not find it encouraging enough to openly receive and assimilate the knowledge, particularly if it has no relevance to the job function of the current subsidiary. The subsidiary's learning capacity is therefore a result of the cognitive abilities of the combined individuals workers.. This accompanied with the appropriate level of competence based trust S2 has in a highattention subsidiary will add to the overall openness between expatriate and S2 colleague and thus plays a pivotal moderating role in altering the knowledge sharing behaviour of expatriates. 
Proposition 7: Greater job/function relevance between an expatriate's previous role and current strengthens the willingness of the new subsidiary to learn and engage in knowledge sharing activities

Accordingly, expatriate motivation to share knowledge from high-attention subsidiaries can be further strengthened through shared job functions as per the argument for self-efficacy (Oddou, Osland, \& Blakeney, 2009). Relevant knowledge derived from similar roles in the previous subsidiary will allow the expatriate to draw on similar developed mental maps for handling comparable situations and problems in the new environment, further enhancing their confidence to share by being in a stronger position of useful and trustworthy knowledge. Consistent with other research, the findings also reflect the work of Foss \& Pedersen (2002) who found similarity across inter-subsidiary functions stimulates attempts to interactively solve problems and hence share knowledge across units. From the point of the senderreceiver model, the effect of shared vision would be considered a positive moderating effect for both parties. Both expatriate and subsidiary colleagues are more likely to share and receive knowledge respectively when strongly tied to similar operational processes (Schultz, 2003).

Proposition 8: Greater job/function relevance between the previous role and current strengthens the expatriate's confidence in knowledge from the prior subsidiary and motivation to share in the subsequent assignment

\subsection{Contribution To Research}

The study provides contributions and implications for the relevant research fields. In dealing with complexities produced by the interaction of formal and informal coordination mechanisms, MNCs rely heavily on expatriation. The current study extends traditional ethnocentric roles of expatriates by acknowledging their role as knowledge transporters across multiple units. Specifically the research contributes by examining those still within the expatriation cycle as limited studies explore expatriate knowledge sharing during real-time movement from one subsidiary to another. This goes beyond the dyadic expatriate-HQ relationships during assignment, 
or extracting knowledge from the expatriate during the repatriation phase. In doing so, the thesis explores lateral knowledge sharing behaviour of the expatriate as a reflection of the dearth of literature surrounding firm level lateral MNC knowledge flows.

Additionally, expatriate outlook on determinants of knowledge sharing is an area of continuous development as the competitive landscape is ever changing. Thus the study addresses the call to add to existing knowledge by investigating new antecedents. Under the assumption of self-efficacy and competence-based trust, the perceived benefits to knowledge recipients is contingent on the perceived value of knowledge which enabled the research to explore origins of superior knowledge (Kang and Hau, 2014). Therefore, the final and most important contribution of the research is in extending the attention-based view, specifically HQ attention as an influencer of organisational actions to a new domain within the knowledge-sharing context. The ABV describe HQ attention as a desirable resource, the allocation of which is often unequally distributed, creating enhanced knowledge in some subsidiaries relative to others. Studies have since explored the role of HQ Attention on subsidiary outcomes; behaviour and more recently, reverse knowledge sharing at the subsidiary level.

This highlighted an important gap linking subsidiary outcomes characterised by unequal distribution of HQ attention to individual level outcomes. Taking into account the current antecedents of expatriate knowledge sharing, the research contributes a novel relationship between subsidiary level outcomes and its role in the context of the individual. Thus exploring the role of HQ attention disparity as a new possible antecedent of expatriate knowledge sharing. This goes beyond the overgeneralised concepts of personality; individual absorptive capacity and careeroriented issues and hence we make important contributions to both the knowledge management and ABV literature, which are yet to be researched in conjunction with one another. Resultantly, the thesis signifies the vitality of expatriates in tending to subsidiaries lacking HQ attention as without, these subsidiaries struggle to gain the necessary contextual knowledge about actions that may also effectively attract headquarters' attention in the future. 


\subsection{Managerial Implications}

The study indicates managerial implications at the headquarter level, subsidiary level and the expatriate level. Revisiting key objectives of expatriation is important, especially if HQ demonstrate an inability to effectively utilise expatriates to mitigate disadvantages of HQAD. HQ-attention should reflect current perceptions that exploitation of knowledge across all units is desired to strategically enhance the firm. Restricting expatriates to strategic subsidiaries in specific regions contradicts these objectives. Under the assumption attention is unequally distributed, MNC objectives can be reached by sending expatriates from high-attention subsidiaries to subsidiaries that receive minimal. HQ may wish to further consider ways to increase expatriate's awareness about the value of their knowledge to other units. Alignment of job roles between assignments is also critical as it mitigates uncertainty to the usefulness of the expatriate. Re-evaluation of expatriate positioning is necessary as is designing assignments with knowledge sharing initiatives in mind. Evaluation of the expatriate's legitimacy is detrimental to the quality of interactions encountered.

At the firm level, local managers drive subsidiary culture which research argues essentialness toward encouraging subsidiary learning efforts (Gupta and Govindarajan 2000). Frequent communication characterises the dynamic workplace thus colleagues need to be working side-by-side. It is important for local managers to mediate the relationship between expatriate and local staff by regularly revising key subsidiary objectives relative to the goals of the MNC to develop an encouraging atmosphere (Fey and Furu, 2008). Overcoming resistance to learning imply the expatriate should actively seek to integrate into the subsidiary socialisation network to enhance affectbased trust. Parallel to the literature, the study finds that connecting with individuals through social interaction predicates the necessary foundation of trust associated with personal acceptance. In conjunction with competence-trust expatriates can use this as a platform to share knowledge and weaken uncertainty in the process.

\subsection{Limitations and future directions for research}

An inherent limitation of qualitative research is the generalisability of the findings. As this thesis explored a specific phenomenon within a certain context and population, 
generalisability was not an expected attribute. Secondly, the implemented interviews were entirely participant driven and therewith contingent on the interviewee willingness to share in-depth experiences. Participants may hesitate when expressing subjective experiences therefore there is a risk of glossing over insights rather further explanation. Additionally, thematic analysis purports that the coding and analysis of the data is subject to the interpretation of the researcher. Bias is thus recognised as an inevitable limitation despite dedicated efforts. Population sample was another limitation, which forced the research to emphasise an array of experiences and varying subsidiary-HQ relationships across different industries. Replication of the research using one case study can paint a better picture of the found effects by referring to the actions of a focal headquarters.

The first recommendation is to quantitatively test the study propositions in order to address the limitation of generalisability. Secondly, future studies should seek to use of narrower knowledge sharing or knowledge transfer definitions to see if the results still hold. Furthermore, the research found the contingency of the HQAD-knowledge sharing relationship to be effected by job/function relevance. Future research could interpret responses between middle managers and top managers can confirm the validity of the effect of internal variables. The research also found interesting opinions of the fairness in attention allocation with respect to hostility. A focal study exploring the effects of subsidiary attitudes of attention fairness would be an interesting contribution to the knowledge sharing literature. Lastly, an option would be to conduct the research from the firm's point of view by focusing on subsidiary colleagues to measure the success of expatriate's knowledge sharing. These recommendations may therefore require a larger sample size in order to make overviews more confidently.

\subsection{Conclusive remarks}

In conclusion, while earlier research has meticulously researched knowledge sharing, little is known on whether variances in corporate actions at the subsidiary level has linkages to the knowledge sharing of an expatriate. Thus the qualitative study implemented multiple semi-structured interviews to explore expatriate knowledge sharing as being subject to a new antecedent: Headquarter Attention Disparity. We 
found moreover the traditional assumption of perceived costs of sharing knowledge, the thesis supports similar research that the propensity for an expatriate to share knowledge is related to the perceived benefit of their acquired knowledge from the prior subsidiary to the subsequent subsidiary. This key finding was more prevalent when the knowledge origins from a subsidiary that received higher levels of HQ attention compared to the next. The nature of knowledge sharing continuously adapts to reflect the global environment however the current study hopes to have shed some additional light on the expatriate knowledge sharing process by introducing novel relationships. 


\subsection{REFERENCES}

Adler, N. J., \& Bartholomew, S. (1992). Academic and professional communities of discourse: Generating knowledge on transnational human resource management. Journal of International Business Studies, 23(3), 551-569.

Alavi, M., Kayworth, T. R., \& Leidner, D. E. (2005). An empirical examination of the influence of organizational culture on knowledge management practices. Journal of management information systems, 22(3), 191-224.

Ambos, T. C., Ambos, B., \& Schlegelmilch, B. B. (2006). Learning from foreign subsidiaries: An empirical investigation of headquarters' benefits from reverse knowledge transfers. Intenrational Business Review , 15, 294-312.

Anatan, L. (2013). A proposed framework of university to industry knowledge transfer: Dyadic relationship in university to industry knowledge transfer. Review of Integrative Business \& Economics Research, 2, 304-325.

Andersson, U., Björkman, I., \& Forsgren, M. (2005). Managing subsidiary knowledge creation: The effect of control mechanisms on subsidiary local embeddedness. International Business Review, 14(5), 521-538.

Anne Crowne, K. (2009). Enhancing knowledge transfer during and after international assignments. Journal of Knowledge Management, 13, 134-147.

Antal, A. B. (2001). Expatriates' Contributions to Organizational Learning1. Journal of General Management, 26(4), 62-84.

Argote, L., \& Ingram, P. (2000). Knowledge transfer: A basis for competitive advantage in firms. Organizational Behavior and Human Decision Processes, 82, $150-169$. 
Argote, L., McEvily, B., \& Reagans, R. (2003). Managing knowledge in organizations: An integrative framework and review of emerging themes. Management Science, 49, 571-582.

Audretsch, D., \& Aldridge, T. (2012). Transnational social capital and scientist entrepreneurship. Journal of Management and Governance, 16, 369-376.

Barry Hocking, J., Brown, M., \& Harzing, A. (2004). A knowledge transfer perspective of strategic assignment purposes and their path-dependent outcomes. The International Journal of Human Resource Management, 15, 565-586.

Bender, S., \& Fish, A. (2000). The transfer of knowledge and the retention of expertise: the continuing need for global assignments. Journal of knowledge management, 4(2), 125-137.

Berthoin-Antal, A. (2000). Types of knowledge gained by expatriate managers. Journal of General Management , 26, 32-51.

Birkinshaw, J. (1997). Entrepreneurship in multinational corporations: The characteristics of subsidiary initiatives. Strategic management journal, 18(3), 207229.

Birkinshaw, J. (2000). Determinants and consequences of subsidiary initiative in multinational corporations. Entrepreneurship Theory and Practice, 24(1), 9-35.

Birkinshaw, J., Bouquet, C., and Ambos, T.C. (2007). Managing executive attention in the global company. MIT Sloan Management Review, 48(4), 39-45.

Björkman, I., Barner-Rasmussen, W., \& Li, L. (2004). Managing knowledge transfer in MNCs: The impact of headquarters control mechanisms. Journal of international business studies, 35(5), 443-455. 
Bock, G. W., Zmud, R. W., Kim, Y. G., \& Lee, J. N. (2005). Behavioral intention formation in knowledge sharing: Examining the roles of extrinsic motivators, socialpsychological forces, and organizational climate. MIS quarterly, 87-111.

Bonache, J., \& Brewster, C. (2001). Knowledge transfer and the management of expatriation . Thunderbird International Business Review , 43, 145-168.

Bonache, J., \& Zárraga-Oberty, C. (2008). Determinants of the success of international assignees as knowledge transferors: A theoretical framework. The International Journal of Human Resource Management, 19(1), 1-18.

Bouquet, C., \& Birkinshaw, J. (2008). Weight versus voice: How foreign subsidiaries gain attention from corporate headquarters. Academy of Management journal, 51(3), $577-601$

Bouquet, C., Morrison, A., \& Birkinshaw, J. (2009). International attention and multinational enterprise performance. Journal of International Business Studies, 40, $1,108-131$.

Boyatzis, R. E. (1998). Transforming qualitative information: Thematic analysis and code development. Thousand Oaks, CA: Sage.

Braun, V., \& Clarke, V. (2006). Using thematic analysis in psychology. Qualitative Research in Psychology, 3(2), 77-101.

Brown, J. S., \& Duguid, P. (2001). Knowledge and organization: A social-practice perspective. Organization science, 12(2), 198-213.

Bryman, A. (2001). The nature of qualitative research. Social research methods, 365399.

Cabrera, A., Collins, W. C., \& Salgado , J. F. (2006). Determinants of individual engagement in knowledge sharing. International Journal of Human Resource Management , 17 (2), 245-264. 
Cabrera, E. (2003). Socio-psychological aspects of knowledge sharing in organizations. In Proceedings of the 7th Conference on International Human Resource Management, Limerick (pp. 4-6).

Castañeda, Z., \& Ignacio, D. (2015). Knowledge sharing: The role of psychological variables in leaders and collaborators. Suma Psicológica, 22(1), 63-69.

Chandler Jr, A. D. (1991). The functions of the HQ unit in the multi-business firm. Strategic management journal, 12[S2], 31-50.

Chang, Y. Y., Gong, Y., \& Peng, M. W. (2012). Expatriate knowledge transfer, subsidiary absorptive capacity, and subsidiary performance. Academy of Management Journal, 55, 927-948.

Chiu, C. M., Hsu, M. H., \& Wang, E. T. (2006). Understanding knowledge sharing in virtual communities: An integration of social capital and social cognitive theories. Decision support systems, 42(3), 1872-1888.

Chow, W. S., \& Chan, L. S. (2008). Social network, social trust and shared goals in organizational knowledge sharing. Information and Management, 45, 458-465.

Chowdhury, S. (2005). The role of affect-and cognition-based trust in complex knowledge sharing. Journal of Managerial issues, 310-326.

Chung, L. (2014). Headquarters' managerial intentionality and reverse transfer of practices. Management International Review, 54(2), 225-252.

Ciabuschi, F., Dellestrand, H., \& Nilsson, A. C. (2015). Value generation in the multinational corporation. In The future of global organizing (pp. 39-56). Emerald Group Publishing Limited. 
Ciabuschi, F., Martin , O. M., \& Stahl , B. (2010). Headquarters' Influence on Knowledge Transfer Performance . Management International Review , 50 (4), 471491.

Cohen, S. M., Curd, P., \& Reeve, C. D. C. (2016). Readings in ancient Greek philosophy: From Thales to Aristotle. Indianapolis, IN: Hackett Publishing.

Collis, D. J., \& Montgomery, C. A. (1998). Creating corporate advantage (pp. 7183). Harvard Business School.

Collis, D., Young, D., \& Goold, M. (2007). The size, structure, and performance of corporate headquarters. Strategic Management Journal, 28(4), 383-405.

Criscuolo, P., \& Narula, R. (2007). Using multi-hub structures for international R\&D: organisational inertia and the challenges of implementation. Management International Review, 47(5), 639-660.

Cuervo-Cazurra, Á., \& Un, C. A. (2004). Firm-specific and non-firm-specific sources of advantage in international competition. In Creating value through international strategy(pp. 78-94). Palgrave Macmillan, London.

Cummings, J. L., \& Teng, B. S. (2003). Transferring R\&D knowledge: The key factors affecting knowledge transfer success. Journal of Engineering and Technology Management, 20, 39-68.

Cyr, S., \& Wei Choo, C. (2010). The individual and social dynamics of knowledge sharing: an exploratory study. Journal of Documentation, 66(6), 824-846.

Dalkir, K. 2005. Knowledge management in theory and practice. Amsterdam: Elsevier/Butterworth Heinemann.

Dellestrand, H. (2011). Subsidiary embeddedness as a determinant of divisional headquarters involvement in innovation transfer processes. Journal of International Management, 17(3), 229-242. 
Denrell, J., Arvidsson, N., and Zander, U. (2004). Managing knowledge in the dark: An empirical study of the reliability of capability evaluations. Management Science, 50(11), 1491-150.

Denzin, N. K., \& Lincoln, Y. S. (Eds.). (2011). The SAGE handbook of qualitative research. Sage.

Dhanaraj, C., Lyles, M. A., Steensma, H. K., \& Tihanyi, L. (2004). Managing tacit and explicit knowledge transfer in IJVs: The role of relational embeddedness and the impact on performance. Journal of International Business Studies, 35, 428-442.

DiCicco-Bloom, B., \& Crabtree, B. F. (2006). The qualitative research interview. Medical education, 40(4), 314-321.

Dittmar, H., \& Drury, J. (2000). Self-image-is it in the bag? A qualitative comparison between "ordinary" and "excessive" consumers. Journal of economic psychology, 21(2), 109-142.

Dörrenbächer, C., \& Gammelgaard, J. (2016). Subsidiary initiative taking in multinational corporations: the relationship between power and issue selling. Organization studies, 37(9), 1249-1270.

Doz, Y. L., Santos, J., \& Williamson, P. J. (2001). From global to metanational: How companies win in the knowledge economy. Harvard Business Press.

Dubois, A., \& Gadde, L. E. (2002). Systematic combining: an abductive approach to case research. Journal of business research, 55(7), 553-560.

Dunning, J. H. (1998). Location and the multinational enterprise: a neglected factor?. Journal of international business studies, 29(1), 45-66. 
Dunning, J. H. (2001). The eclectic (OLI) paradigm of international production: past, present and future. International journal of the economics of business, 8(2), 173-190 Easterby-Smith, M., Lyles, M. A., \& Tsang, E. W. (2008). Inter-organizational knowledge transfer: Current themes and future prospects. Journal of management studies, 45(4), 677-690.

Elanain, H. M. A. (2009). Job characteristics, work attitudes and behaviors in a nonwestern context: Distributive justice as a mediator. The Journal of Management Development, 28(5), 457-477.

Elsbach, K.D., Barr, P.S., and Hargadon, A.B. (2005). Identifying Situated Cognition in Organizations. Organization Science, 16(4), 422-433.

Endres, M., Endres, S. P., Chowdhury, S. K., \& Alam, I. (2007). Tacit knowledge sharing, self-efficacy theory, and application to the Open Source community. Journal of knowledge management, 11(3), 92-103.

Ensign, P. C. (1999). Innovation in the multinational firm with globally dispersed R\&D: Technological knowledge utilization and accumulation. The Journal of High Technology Management Research, 10(2), 203-221.

Fey, C. F., \& Furu, P. (2008). Top management incentive compensation and knowledge sharing in multinational corporations. Strategic Management Journal, 29, $1301-1323$.

Foos, T., Schum, G., \& Rothenberg, S. (2006). Tacit knowledge transfer and the knowledge disconnect. Journal of knowledge management, 10(1), 6-18.

Forsgren, M., Holm U., and Johanson, J. (2005). Managing the Embedded Multinational. Cheltenham, UK: Edward Elgar Publishing. 
Foss, N. J., \& Pederson, T. (2002). Transferring knowledge in MNCs: The role of sources of subsidiary knowledge and organizational context. Journal of International Management, 8, 49-67.

Fransson, A., Hakanson, L., \& Liesch, P. W. (2011). The underdetermined knowledge-based theory of the MNC. Journal of INternational Business Studies , 42 (3), 427-435.

Frost, T. S., \& Zhou, C. (2005). R\&D co-practice and 'reverse'knowledge integration in multinational firms. Journal of International Business Studies, 36(6), 676-687.

Furuya , N., Stevens , M. J., Bird, A., Oddou, G., \& Mendenhall, M. (2009). Managing the learning and transfer of global management competence: Antecedents and outcomes of Japanese repatriation effectiveness . Journal of International Business Studies , 40 , 200-215.

Fusch, P. I., \& Ness, L. R. (2015). Are we there yet? Data saturation in qualitative research. The qualitative report, 20(9), 1408-1416.

Gao, Y. F. \& Riley, M. (2009). Knowledge and identity: A review. International Journal of Management Reviews, 12, 317- 338.

Garg, V. K., Walters, B. A., \& Priem, R. L. (2003). Chief executive scanning emphases, environmental dynamism, and manufacturing firm performance. Strategic management journal, 24(8), 725-744.

Gavetti, G. and Levinthal, D. (2000). Looking forward and looking backward: Cognitive and experiential search. Administrative Science Quarterly, 45(1), 113-137.

Ghoshal , S., \& Bartlett, C. A. (1990). The Multinational Corporation as an Interorganizational Network . Academy of Management Review , 15 (4), 603-625.

Ghoshal, S., \& Nohria, N. (1989). Internal differentiation within multinational corporations. Strategic management journal, 10(4), 323-337. 
Gonzalez, J. A., \& Chakraborty, S. (2014). Expatriate knowledge utilization and MNE performance: A multilevel framework. Human Resource Management Review, 24(4), 299-312.

Graneheim, U. H., \& Lundman, B. (2004). Qualitative content analysis in nursing research: concepts, procedures and measures to achieve trustworthiness. Nurse education today, 24(2), 105-112.

Gummesson, E. (2003). All research is interpretive!. Journal of business \& industrial marketing, 18(6/7), 482-492.

Gupta, A. K.. \& Govindarajan, V. (2000). Knowledge flows within multinational corporations. Strategic Management Journal, 21, 473-496.

Hakanson, L., \& Nobel, R. (2001). Organizational Characteristics and Reverse Technology Transfer. Management International Review , 41 (4), 395-420.

Hansen, M. T., Nohria, N., \& Tierney, T. (1999). What's your strategy for managing knowledge? Harvard Business Review, 77, 106-116.

Hansen, M.T. and Haas, M.R. (2001). Competing for attention in knowledge markets: Electronic document dissemination in a management consultancy company. Administrative Science Quarterly, 46(1), 1-28.

Harzing, A. W. K. 2001. Of bears, bumblebees, and spiders: The role of expatriates in controlling foreign subsidiaries. Journal of World Business, 36: 366- 379.

Harzing, A.W., Pudelko , M., \& Reiche , B. S. (2016). The Bridging Role of Expatriates and Inpatriates in Knowledge Transfer in Multinational Corporations. Journal of Human Resource Management , 55 (2), 679-695. 
Hatch, N. W., \& Dyer, J. H. (2004). Human capital and learning as a source of sustainable competitive advantage. Strategic management journal, 25(12), 11551178 .

Hau, Y. S., Kim, B., Lee, H., \& Kim, Y. G. (2013). The effects of individual motivations and social capital on employees' tacit and explicit knowledge sharing intentions. International Journal of Information Management, 33(2), 356-366.

Helmstadter, E. (2003). Economics of Knowledge Sharing: A New Institutional Approach. Edward Elgar Publishing, Incorporated.

Hocking , J. B., Brown , M. E., \& Harzing, A.-W. (2007). Balancing global and local strategic contexts: Expatriate knowledge transfer, applications and learning within a transnational organization. Human Resource Management , 46 (4), 513-533.

Holm, U., Pedersen, T., \& Björkman, I. (2000). The emergence and impact of MNC centres of excellence. Basingstoke, UK.

Hsu, M. H., Ju, T. L., Yen, C. H., \& Chang, C. M. (2007). Knowledge sharing behavior in virtual communities: The relationship between trust, self-efficacy, and outcome expectations. International journal of human-computer studies, 65(2), 153 169.

Huang, M.-C., Chiu, Y.-P., \& Lu, T.-C. (2013). Knowledge governance mechanisms and repatriate's knowledge sharing: the mediating roles of motivation and opportunity . Journal of Knowledge Management, 17 (5), 667-694.

Huang, Q., Davison, R. M., Liu, H., \& Gu, J. (2008). The impact of leadership style on knowledge-sharing intentions in China. Journal of Global Information Management (JGIM), 16(4), 67-91.

Husted, K., \& Michailova, S. (2002). Diagnosing and fighting knowledge-sharing hostility. Organizational dynamics, 31(1), 60-73. 
Inkpen, A. C. (1998). Learning and knowledge acquisition through international strategic alliances. Academy of Management Perspectives, 12(4), 69-80.

Inkpen, A. C., \& Tsang, E. W. K. (2005). Social capital, networks, and knowledge transfer. Academy of Management Review, 30, 146-165.

Ipe, M. (2003). Knowledge sharing in organizations: A conceptual framework. Human resource development review, 2(4), 337-359.

Kahneman, D. (1973). Attention and effort. Englewood Cliffs, NJ: Prentice Hall.

Kamoche, K. (1997). Knowledge creation and learning in international HRM. The International Journal of Human Resource Management, 8, 213-225.

Kane, A. A., Argote, L., \& Levine, J. M. (2005). Knowledge transfer between groups via personnel rotation: Effects of social identity and knowledge quality. Organizational Behavior and Human Decision Processes, 96, 56-71.

Kang, M., \& Sauk Hau, Y. (2014). Multi-level analysis of knowledge transfer: A knowledge recipient's perspective. Journal of Knowledge Management, 18, 758-776.

Kaše, R., Paauwe, J., \& Zupan, N. (2009). HR practices, interpersonal relations, and intrafirm knowledge transfer in knowledge-intensive firms: A social network perspective. Human Resource Management, 48, 615-639.

Kim, W.C. and Mauborgne, R.A. (1993). Procedural justice, attitudes, and subsidiary top management compliance with multinationals' corporate strategic decision. Academy of Management Journal, 36(3), 502-526.

Kogut, B., \& Kulatilaka, N. (1994). Operating flexibility, global manufacturing, and the option value of a multinational network. Management science, 40(1), 123-139.

Kogut, B., \& Zander, U. (1996). What firms do? Coordination, identity, and learning. Organization science, 7(5), 502-518. 
Kostova, T. (1999). Transnational Transfer of Strategic Organizational Practices: A Contextual Perspective. The Academy of Management Review , 24 (2).

Kostova, T., \& Roth, K. (2002). Adoption of an organizational practice by subsidiaries of multinational corporations: Institutional and relational effects. Academy of Management Journal, 45, 215-233.

Kumar, N. (2013). Managing reverse knowledge flow in multinational corporations. Journal of Knowledge Management, 17, 695-708.

Lane, P. J., Salk, J. E., \& Lyles, M. A. (2001). Absorptive capacity, learning, and performance in international joint ventures. Strategic Management Journal, 22, 1139 1161.

Lazarova, M., \& Tarique , I. (2005 ). Knowledge transfer upon repatriation . Journal of World Business , 40 , 361-373.

Leana, C. R., \& Pil, F. K. (2006). Social capital and organizational performance: Evidence from urban public schools. Organization Science, 17(3), 353-366.

Leech, B. L. (2002). Asking questions: techniques for semistructured interviews. PS: Political Science \& Politics, 35(4), 665-668.

Leech, N. L., \& Onwuegbuzie, A. J. (2007). An array of qualitative data analysis tools: a call for data analysis triangulation. School psychology quarterly, 22(4), 557.

Leposky, T., Arslan , A., \& Kontkanen , M. (2016). Determinants of reverse marketing knowledge transfer potential from emerging market subsidiaries to multinational enterprises' headquarters . Journal of Strategic Marketing .

Levy, O. (2005). The influence of top management team attention patterns on global strategic posture of firms. Journal of Organizational Behavior, 26(7), 797-819. 
Li, L. (2005). The effects of trust and shared vision on inward knowledge transfer in subsidiaries' intra- and inter- organizational relationships. International Business Review, 14, 77-95.

Loebbecke, C., van Fenema, P. C., \& Powell, P. (2016). Managing interorganizational knowledge sharing. The Journal of Strategic Information Systems, 25(1), 4-14.

Luo, Y. (2005). Toward coopetition within a multinational enterprise: A perspective from foreign subsidiaries. Journal of World Business, 40(1), 71-90.

Luo, Y., Hongxin Zhao, J., \& Du, J. (2005). The internationalization speed of ecommerce companies: an empirical analysis. International Marketing Review, 22(6), 693-709.

Madsen, T. L., Mosakowski, E., \& Zaheer, S. (2003). Knowledge retention and personnel mobility: The nondisruptive effects of inflows of experience. Organization science, 14(2), 173-191.

Martinez, J. I., \& Jarillo, J. C. (1991). Coordination demands of international strategies. Journal of International business studies, 22(3), 429-444.

Maxwell, J. A. (2012). Qualitative research design: An interactive approach (Vol. 41). Sage publications.

McEvoy, G. M., \& Buller, P. F. (2013). Research for practice: The management of expatriates. Thunderbird International Business Review, 55(2), 213-226.

Michailova, S., \& Mustaffa, Z. (2012). Subsidiary knowledge flows in multinational corporations: Research accomplishments, gaps, and opportunities. Journal of World Business, 47(3), 383-396.

Minbaeva, D. B., \& Michailova, S. (2004 ). Knowledge transfer and expatriation in multinational corporations: The role of disseminative capacity . Employee Relations , $26(6), 663-679$. 
Minbaeva, D., Pedersen , T., Bjorkman , I., Fey , C. F., \& Park , H. J. (2003). MNC Knowledge Transfer, Subsidiary Absorptive Capacity, and HRM . Journal of International Business Studies , 34 (6), 586-599.

Molinsky, A. (2007). Cross-cultural code-switching: The psychological challenges of adapting behavior in foreign cultural interactions. Academy of Management Review, $32,622-640$.

Monteiro, L. F. (2015). Selective attention and the initiation of the global knowledgesourcing process in multinational corporations. Journal of International Business Studies, 46(5), 505-527.

Monteiro, L.F. (2015). Selective attention and the initiation of the global knowledgesourcing process in multinational corporations. Journal of International Business Studies, 46(5), 505-527.

Monteiro, L.F., Arvidsson, N., and Birkinshaw, J. (2008). Knowledge flows within multinational corporations: Explaining subsidiary isolation and its performance implications. Organization Science, 19(1), 90-107.

Mooradian, T., Renzl, B., \& Matzler, K. (2006). Who trusts? Personality, trust and knowledge sharing. Management learning, 37(4), 523-540.

Morrison, E. W. (1993). Newcomer information seeking: Exploring types, modes, sources, and outcomes. Academy of management Journal, 36(3), 557-589.

Morrison, E.W. (2014). Employee Voice and Silence. Annual Review of Organizational Psychology and Organizational Behaviour, 1, 173-179.

Mudambi , R., Piscitello , L., \& Rabbiosi , L. (2014). Reverse Knowledge Transfer in MNEs: Subsidiary Innovativeness and Entry Modes . Long Range Planning , 47, 4963. 
Nahapiet, J., \& Ghoshal, S. (1998). Social capital, intellectual capital, and the organizational advantage. Academy of Management Review, 23, 242-266.

Nair, S., Demirbag, M., \& Mellahi, K. (2016). Reverse Knowledge Transfer in Emerging Market Multinationals: The Indian Context . International Business Review , 25 (1), 152-164.

Najafi-Tavani, Z., Giroud , A., \& Sinkovics , R. R. (2012). Mediating Effects in Reverse Knowledge Transfer Processes: The Case of Knowledge- Intensive Services in the U.K . Management International Review , 52 (3), 461-488.

Najafi-Tavani, Z., Zaefarian, G., Naude, P., \& Giroud , A. (2015). Reverse knowledge transfer and subsidiary power . Industrial Marketing Management , 48, 103-110.

Nell, P. C., \& Ambos, B. (2013). Parenting advantage in the MNC: An embeddedness perspective on the value added by headquarters. Strategic Management Journal, 34(9), 1086-1103.

Nery-Kjerfve, \& McLean , G. N. (2012). Repatriation of expatriate employees, knowledge transfer, and organizational learning: What do we know? . European Journal of Training and Development , 36 (6), 614-629.

Nery-Kjerfve, T., \& McLean, G. N. (2012). Repatriation of expatriate employees, knowledge transfer, and organizational learning: What do we know? European Journal of Training and Development, 36, 614-629.

Nonaka, I. and Takeuchi, H. 2011. The wise leader. Harvard Business Review, 89 (5), pp. 58-67.

Nonaka, I., \& Takeuchi, H. (1995). The knowledge-creating company. London: Oxford University Press. 
Noorderhaven, N. and Harzing, A. 2009. Knowledge-sharing and social interaction within MNEs.Journal of International Business Studies, 40 (5), pp. 719-741.

Nooshinfard, F., \& Nemati-Anaraki, L. (2014). Success factors of inter-organizational knowledge sharing: a proposed framework. The Electronic Library, 32(2), 239-261.

Ocasio, W. (2011). Attention to attention. Organization science, 22(5), 1286-1296.

Oddou, G., Osland, J. S., \& Blakeney, R. N. (2009). Repatriating knowledge: variables influencing the "transfer'" process. Journal of International Business Studies , 40 , 181-199.

Oddou, G., Szkudlarek , B., Osland, J. S., Deller, J., Blakeney , R., \& Furuya, N. (2013). Repatriates as a Source of Competitive Advantage: How to manage knowledge transfer . Organisational Dynamics , 42, 257-266.

Osterloh, M., \& Frey, B. S. (2000). Motivation, knowledge transfer, and organizational forms. Organization science, 11(5), 538-550.

Paterson, S. L., \& Brock, D. M. (2002). The development of subsidiary-management research: review and theoretical analysis. International Business Review, 11(2), 139163.

Patton, M. Q. (1990). Qualitative evaluation and research methods. SAGE Publications, inc.

Patton, M. Q. (1999). Enhancing the quality and credibility of qualitative analysis. Health services research, 34(5 Pt 2), 1189.

Perlmutter, H. V. (2017). The tortuous evolution of the multinational corporation. In International Business (pp. 117-126). Routledge. 
Plourde, Y., Parker, S. C., \& Schaan, J. L. (2014). Expatriation and its effect on headquarters' attention in the multinational enterprise. Strategic Management Journal, 35(6), 938-947.

Porter, M. E. (1990). New global strategies for competitive advantage. Planning Review, 18(3), 4-14.

Posner, M. and Boies, S. J. (1971). Components of attention. Psychological Review, $78(5), 391-408$

Razak , N. A., Pangil , F., Md Zin , M., Azlina , N., Yunus , M., \& Asnawi , N. H. (2016). Theories of Knowledge Sharing Behavior in Business Strategy. Procedia Economics and Finance, 37, 545-553.

Reiche , B. S., Harzing , A.-W., \& Kraimer, M. L. (2009). The role of international assignees' social capital in creating inter-unit intellectual capital: a cross-level model. Journal of International Business Studies , 40, 509-526.

Reiche, B. S. (2012). Knowledge Benefits of Social Capital upon Repatriation: A Longitudinal Study of International Assigneesjoms_1050 1 . Journal of Management Studies , 49 (6).

Rerup, C. (2009). Attentional triangulation: Learning from unexpected rare crises. Organization Science, 20(5), 876-893.

Rhodes, J., Hung, R., Lok, P., Ya-Hui Lien, B., \& Wu, C. M. (2008). Factors influencing organizational knowledge transfer: implication for corporate performance. Journal of knowledge management, 12(3), 84-100.

Riusala , K., \& Smale, A. (2007). Predicting Stickiness Factors in the International Transfer of Knowledge through Expatriates. International Studies of Management \& Organisation , 37 (3), 16-43. 
Riusala, K., \& Suutari, V. (2004). International knowledge transfers through expatriates. Thunderbird International Business Review, 46(6), 743-770.

Rugman, A. (2006). Inside the multinationals 25th anniversary edition: the economics of internal markets. Springer.

Saka-Helmhout, A. (2007). Unravelling learning within multinational corporations. British Journal of Management, 18(3), 294-310.

Sanchez-Vidal, M. E., Sanz-Valle , R., \& Barba-Aragon, M. (2016). Repatriates and reverse knowledge transfer in MNCs . The International Journal of Human Resource Management .

Sankowska, A. (2013). Relationships between organizational trust, knowledge transfer, knowledge creation, and firm's innovativeness. The Learning Organization, 20(1), 85-100.

Saunders, M., Lewis, P., \& Thornhill, A. (2009). Research methods for business students. Pearson education.

Schwandt, T. A., Lincoln, Y. S., \& Guba, E. G. (2007). Judging interpretations: But is it rigorous? Trustworthiness and authenticity in naturalistic evaluation. New directions for evaluation, 2007(114), 11-25.

Spiggle, S. (1994). Analysis and interpretation of qualitative data in consumer research. Journal of consumer research, 21(3), 491-503.

Stroh, L. K., Gregersen, H. B. and Black, J. S. (2000). 'Triumphs and tragedies: expectations and commitments upon repatriation'. International Journal of Human Resource Management, 11, 681-97.

Suppiah, V., \& Singh Sandhu, M. (2011). Organisational culture's influence on tacit knowledge-sharing behaviour. Journal of knowledge management, 15(3), 462-477. 
Swift, M., Balkin, D. B., \& Matusik, S. F. (2010). Goal orientations and the motivation to share knowledge. Journal of Knowledge Management, 14(3), 378-393.

Szulanski, G. (1996). Exploring internal stickiness: Impediments to the transfer of best practice within the firm. Strategic Management Journal, 17, 27-43.

Szulanski, G. (2000). The process of knowledge transfer: A diachronic analysis of stickiness. Organizational Behavior and Human Decision Processes, 82, 9-27.

Szulanski, G., Cappetta, R., \& Jensen, R. J. (2004). When and how trustworthiness matters: Knowledge transfer and the moderating effect of causal ambiguity. Organization Science, 15, 600-613.

Tan, H., Wilson, A., \& Olver, I. (2009). Ricoeur's theory of interpretation: An instrument for data interpretation in hermeneutic phenomenology. International Journal of Qualitative Methods, 8(4), 1-15.

Thomas, D. R. (2006). A general inductive approach for analyzing qualitative evaluation data. American journal of evaluation, 27(2), 237-246.

Toh, S. M., \& DeNisi, A. S. (2005). A local perspective to expatriate success. Academy of Management Perspectives, 19(1), 132-146.

Tregaskis, O. (2003). Learning networks, power and legitimacy in multinational subsidiaries. International Journal of Human Resource Management, 14(3), 431-447.

Tsai, W. (2001). Knowledge transfer in intraorganizational networks: Effects of network position and absorptive capacity on business unit innovation and performance. Academy of management journal, 44(5), 996-1004.

Tsai, W., \& Ghoshal, S. (1998). Social capital and value creation: The role of intrafirm networks. Academy of Management Journal, 41, 464-476. 
Tsoukas, H., \& Mylonopoulos, N. (2004). Introduction: Knowledge construction and creation in organizations. British Journal of Management, 15[S1], S1-S8.

Tsoukas, H., \& Vladimirou, E. (2001). What is organizational knowledge?. Journal of management studies, 38(7), 973-993.

Vahlne, J. E., \& Johanson, J. (2014). Replacing traditional economics with behavioral assumptions in constructing the Uppsala Model: toward a theory on the evolution of the Multinational Business Enterprise (MBE). In Multidisciplinary Insights from New AIB Fellows (pp. 159-176). Emerald Group Publishing Limited.

Van Maanen, J., \& Laurent, A. (1993). The flow of culture: some notes on globalization and the multinational corporation. In Organization theory and the multinational corporation (pp. 275-312). Palgrave Macmillan, London.

van Wijk, R., Jansen, J. J. P., \& Lyles, M. A. (2008). Inter- and intra-organizational knowledge transfer: A meta- analytic review and assessment of its antecedents and consequences. Journal of Management Studies, 45, 830-853.

Verbeke, A. (2013). International business strategy. Cambridge University Press.

Virta, M. (2011). Knowledge Sharing Between Generations in an OrganisationRetention of the Old Or Building the New? . Lappeenranta University of Technology.

Wang, C. C., \& Yang, Y. J. (2007). Personality and intention to share knowledge: An empirical study of scientists in an R\&D laboratory. Social Behavior and Personality: an international journal, 35(10), 1427-1436.

Wang, S., \& Noe, R. A. (2010). Knowledge sharing: A review and directions for future research. Human resource management review, 20(2), 115-131.

Welch, C., \& Piekkari, R. (2006). Crossing language boundaries: Qualitative interviewing in international business. Management International Review, 46(4), 417437. 
Whiting, L. S. (2008). Semi-structured interviews: Guidance for novice researchers. Nursing Standard, 22(23), 35-40.

Wright, P. M., Dunford, B. B., \& Snell, S. A. (2001). Human resources and the resource based view of the firm. Journal of management, 27(6), 701-721.

Yang, Q., Mudambi , R., \& Meyer, K. E. (2008). Conventional and Reverse Knowledge Flows in Multinational Corporations. Journal of Management , 34 (5), $882-902$.

Zahra, S. A., \& George, G. (2002). Absorptive capacity: A review, reconceptualization, and extension. Academy of management review, 27(2), 185-203. 


\subsection{Appendices}

\subsection{Interview Guide}

1. Tell me about your experiences across both assignments

2. In your opinion, how did your prior subsidiary compare in importance relative to your current subsidiary?

3. What was experience with headquarters like in either subsidiary?

a. How was this shown?

4. Were there obvious differences of HQ Attention across your assignments?

5. What type of knowledge do you feel that you gained from this assignment?

6. What was your subsequent subsidiaries perception of your prior subsidiary? a. Why?

7. What situations would you often find yourself sharing knowledge?

8. What was your experience when you shared information learnt in your first subsidiary with your colleagues in the new subsidiary?

9. How encouraged were you to share knowledge?

10. What are your thoughts on subsidiary importance of your prior assignment impacting your new colleagues desire for external knowledge?

11. What do you think about expatriate behaviour being influenced by how important the subsidiary is perceived by headquarters?

12. Do you think we have missed anything important? Is there anything else you would like to add? 


\subsection{Participant Information Sheet}

Role of Headquarter Attention Disparity on Expatriate Knowledge Sharing

Between Assignments

\section{INFORMATION SHEET FOR PARTICIPANTS}

You are invited to take part in this research. Please read this information before deciding whether or not to take part. If you decide to participate, thank you. If you decide not to participate, thank you for considering this request.

\section{Who am I?}

My name is Sachinie Wanasinghe and I am a Masters student in the International Business programme at Victoria University of Wellington. This research project is work towards my thesis.

\section{What is the aim of the project?}

This project will explore whether the attention subsidiaries receive from headquarters (HQ) will have an impact on expatriate knowledge sharing between subsidiaries.

Headquarter attention refers to positive recognition and actions taken by a Headquarters toward their subsidiaries (Occasio, 2011).

This research has been approved by the Victoria University of Wellington Human Ethics Committee: Application Number \#0000025745

\section{How can you help?}

You have been invited to participate because you are a previous/current expatriate of an $\mathrm{MNC}$ who has/had been posted between different subsidiaries. If you agree to take part I would like to interview you and ask you questions about your knowledge sharing experience as an expatriate for different subsidiaries. The interview will take approximately 30-60 minutes. I will audio record the interview with your permission 
and transcribe later. You can choose to not answer any question or stop the interview at any time, without giving a reason. You can withdraw from the study by contacting me at any time before the $5^{\text {th }}$ May 2018. If you withdraw, the information you provided will be destroyed or returned to you.

\section{What will happen to the information you give?}

This research is confidential. This means that the researchers named below will be aware of your identity but the research data will be combined and your identity will not be revealed in any reports, presentations, or public documentation. Only my supervisor and I will read the notes or transcript of the interview. The interview transcripts, summaries and any recordings will be kept securely and destroyed on $15^{\text {th }}$ of July 2021.

\section{What will the project produce?}

The information from my research will be used in Master thesis and potential academic publications and conferences.

\section{If you accept this invitation, what are your rights as a research participant?}

You do not have to accept this invitation if you don't want to. If you do decide to participate, you have the right to:

- Choose not to answer any question;

- $\quad$ Ask for the recorder to be turned off at any time during the interview

- Withdraw from the study before $30^{\text {th }}$ of May 2018

- $\quad$ Ask any questions about the study at any time;

- $\quad$ Receive a copy of your interview transcript

- $\quad$ Read over and comment on a written summary of your interview

\section{If you have any questions or problems, who can you contact?}

If you have any questions, either now or in the future, please feel free to contact: 
Student:

Name: Sachinie Wanasinghe

University email address:

Sachinie.wanasinghe@vuw.ac.nz

\section{Supervisor:}

Name: Dr Yang Yu

Role: Senior Lecturer at Victoria

University

School: School of Marketing and

International Business

Phone: 044636486

Yang.yu@vuw.ac.nz

\section{Human Ethics Committee information}

If you have any concerns about the ethical conduct of the research you may contact the Victoria University HEC Convenor: Associate Professor Susan Corbett. Email susan.corbett@vuw.ac.nz or telephone+64-4-4635480. 